\title{
On the Interpretation of the North Atlantic Averaged Sea Surface Temperature
}

\author{
JING SUN \\ GEOMAR Helmholtz Centre for Ocean Research Kiel, Kiel, Germany, and Ocean University of China, Qingdao, China \\ MOJIB LATIF \\ GEOMAR Helmholtz Centre for Ocean Research Kiel, and University of Kiel, Kiel, Germany \\ WONSUN PARK \\ GEOMAR Helmholtz Centre for Ocean Research Kiel, Kiel, Germany \\ TAEWOOK PARK \\ Korea Polar Research Institute, Incheon, South Korea
}

(Manuscript received 26 February 2019, in final form 18 April 2020)

\begin{abstract}
The North Atlantic (NA) basin-averaged sea surface temperature (NASST) is often used as an index to study climate variability in the NA sector. However, there is still some debate on what drives it. Based on observations and climate models, an analysis of the different influences on the NASST index and its low-pass filtered version, the Atlantic multidecadal oscillation (AMO) index, is provided. In particular, the relationships of the two indices with some of its mechanistic drivers including the Atlantic meridional overturning circulation (AMOC) are investigated. In observations, the NASST index accounts for significant SST variability over the tropical and subpolar NA. The NASST index is shown to lump together SST variability originating from different mechanisms operating on different time scales. The AMO index emphasizes the subpolar SST variability. In the climate models, the SST-anomaly pattern associated with the NASST index is similar. The AMO index, however, only represents pronounced SST variability over the extratropical NA, and this variability is significantly linked to the AMOC. There is a sensitivity of this linkage to the cold NA SST bias observed in many climate models. Models suffering from a large cold bias exhibit a relatively weak linkage between the AMOC and AMO and vice versa. Finally, the basin-averaged SST in its unfiltered form, which has been used to question a strong influence of ocean dynamics on NA SST variability, mixes together multiple types of variability occurring on different time scales and therefore underemphasizes the role of ocean dynamics in the multidecadal variability of NA SSTs.
\end{abstract}

\section{Introduction}

The North Atlantic (NA) basin-averaged sea surface temperature (NASST) is often used to discuss mechanisms of SST variability over the NA region. An example is the Atlantic multidecadal oscillation or variability (AMO or AMV, AMO hereafter) index (Kerr 2000; Knight et al. 2005), which is characterized by multidecadal variations in NASST (e.g., Deser and Blackmon 1993; Kushnir 1994; Kilbourne et al. 2008). Climate variations over many regions have been linked to the AMO index. Examples are Northeast Brazilian

Corresponding author: Jing Sun, jsun@geomar.de and Sahel rainfall (Folland et al. 1986; Rowell et al. 1995), coastal climate around the NA (Enfield et al. 2001; Sutton and Hodson 2005), Atlantic hurricanes (Goldenberg et al. 2001), and Arctic sea ice (Day et al. 2012; Swart et al. 2015).

The mechanism of the AMO is not clear (Zhang et al. 2019). It is still under debate what the relative role is of processes such as stochastic atmospheric forcing, ocean dynamics, air-sea interactions, or external forcing (e.g., Latif and Keenlyside 2011; Ting et al. 2014; Bellomo et al. 2018). Moreover, in many studies the AMO is regarded as a physical mode with well-defined spatial pattern and period and unique mechanism, which is not justified on the basis of the current literature. Climate 
models suggest that the low-frequency SST variability over the NA is partly related to the Atlantic meridional overturning circulation (AMOC) (e.g., Delworth et al. 1993; Timmermann et al. 1998; Delworth and Mann 2000; Latif et al. 2004; Knight et al. 2005; Msadek et al. 2013; McCarthy et al. 2015; Kim et al. 2018a,b). In these models, a strong AMOC is associated with an enhanced northward heat transport, which leads to anomalously warm NA SST and vice versa. Further, some previous work has shown that the AMOC can drive a monopolar SST anomaly pattern on multidecadal time scales that bears resemblance to the well-known AMO "horseshoe" SST pattern (e.g., Knight et al. 2005; Danabasoglu et al. 2012).

There are several methods of defining an AMO index from SST observations. The traditional definition is based on the area-weighted, linear detrended, and lowpass filtered NA-averaged $\left(0^{\circ}-60^{\circ} \mathrm{N}\right)$ SST anomalies (Enfield et al. 2001). The method of linear detrending cannot cleanly separate the internal multidecadal variability from the nonlinear externally forced global-scale signal including anthropogenic variability (Trenberth and Shea 2006; Frankcombe and England 2015). Besides linear detrending, other methods have been used to remove the global-scale externally forced signal, for example by using global mean SST as a proxy (Trenberth and Shea 2006; Mann and Emanuel 2006) or a signal-tonoise ratio maximizing empirical orthogonal function (EOF) analysis (Ting et al. 2009; Ruprich-Robert et al. 2017).

Some studies suggest that an SST-based AMO definition is insufficient to understand the mechanism of the AMO because it reflects multivariate low-frequency variability involving, for example, changes in salinity, ocean heat content, surface heat flux, subsurface temperature, and so on (e.g., Zhang 2007; Wang et al. 2010; Robson et al. 2012). A multivariate AMO index based on multivariate empirical orthogonal function (MEOF) analysis has been defined by Yan et al. (2019). Here we stick to the SST and study in detail SST-based indices defined over different regions and time scales with respect to their relationships to different phenomena such as the North Atlantic Oscillation (NAO) or El NiñoSouthern Oscillation (ENSO), and linkages to ocean circulation. As SST is available for one and a half centuries, it can be used to study North Atlantic variability on time scales up to multidecadal.

In climate models, extratropical SST variability over the NA is often related to the AMOC on multidecadal time scales (Latif et al. 2004). Previous studies suggested that the relationship between AMOC and NA SST varies with latitude and time scale. At higher latitudes, the AMOC tends to lead the SST with a longer lead time than at lower latitudes (Zhang 2010; Wang and Zhang 2013). Several climate models studies have illustrated that the AMOC-induced heat transport cannot directly account for SST variability across the entire NA but influences SST mostly over the subpolar region on longer time scales (Zhang and Zhang 2015). Further, it has been suggested by several studies that multiyear to multidecadal SST variability over the subpolar NA is largely due to the delayed response of the oceanic winddriven and meridional overturning circulation to the low-frequency portion of the NAO variability, which in turn drive changes in meridional heat transport (Eden and Willebrand 2001; Delworth et al. 2017).

With regard to tropical NA SST, some other mechanisms are needed to explain the variability such as cloud feedback (Brown et al. 2016; Yuan et al. 2016), local and large-scale wind changes (Carton et al. 1996; Kushnir et al. 2002; Hodson et al. 2014), changes in atmospheric circulation and intertropical convergence zone (ITCZ) shifts (Zhang and Delworth 2005; Robson et al. 2014), or thermodynamic coupled processes such as the windevaporation-SST (WES) feedback (Xie and Carton 2004; Amaya et al. 2017). Remote forcing by ENSO also accounts for a significant fraction of tropical NA SST variability (Enfield and Mayer 1997).

Recently, based on the simulations with atmosphere models coupled to slab-ocean models, some studies suggested that the AMO largely originates from stochastic forcing by the atmosphere (Clement et al. 2015; Cane et al. 2017), specifically the NAO. On the contrary, other recent studies suggested that stochastic atmospheric forcing alone cannot explain and ocean dynamics is crucial in generating NA SST multidecadal variability (O'Reilly et al. 2016; Zhang et al. 2016; Delworth et al. 2017; Zhang 2017; Garuba et al. 2018; Wills et al. 2019). Again other studies argue that the AMO is mostly driven by external forcing due to solar or atmospheric aerosol loading variability (Otterå et al. 2010; Booth et al. 2012). The role of aerosols in driving NA SST during the instrumental record, however, has been challenged by Zhang et al. (2013) by pointing out differences between the climate model simulation results of Booth et al. (2012) and the observations.

In this study we provide an interpretation of the annual basin-averaged NA SST, here referred to as NASST index, as well as of its low-pass filtered version, which serves as AMO index, and investigate the usefulness of the two indices in discussing origins of NA SST variability. We mainly address two questions. First, which processes contribute to the basin-averaged NA SST and on which time scale? Second, can the AMO, when defined by basin-averaged SST, be considered as a physical mode with well-defined spatial pattern and 
period and unique mechanism? We study the influences of the NAO, AMOC, subpolar gyre (SPG), ENSO, and local and remote forcing on the SSTs over different regions of the NA. Most of these aspects have been studied previously and the results have been published in a number of complementary papers, as described above. Here, we investigate systematically how the different drivers are reflected in the NASST index and in the AMO index, two indices that are widely used in studies addressing climate variability over the NA sector and beyond.

We make use of observations and simulations with a number of climate models. Our focus is on internal variability and we therefore removed from the observations an estimate of the externally forced signal. Model data are from control runs without external forcing. We find that when calculated from instrumental SSTs, both the NASST index and the AMO index are composed of SST variability originating from different mechanisms operating on different time scales and therefore do not record a single mode of the climate system over the NA. In the climate models, there is a clear time scale separation such that the AMO index only describes SST variability over the extratropical NA, and this is significantly linked to the AMOC.

The paper is organized as follows: the data, climate models, and statistical methods used in this study are briefly described in section 2 . Section 3 provides the results of our analysis pertaining to the SST variability over the NA. A summary and discussion of the major results are presented in section 4.

\section{Material and methods}

\section{a. Data, climate models, and statistical methods}

Observed SSTs during 1856-2010 with $2^{\circ} \times 2^{\circ}$ resolution are from the Extended Reconstructed Sea Surface Temperature version 5 dataset (ERSST.v5, Huang et al. 2017). The NASST index is defined here as the annual SST anomalies over the NA averaged over the region $0^{\circ}-60^{\circ} \mathrm{N}, 7.5^{\circ}-75^{\circ} \mathrm{W}$. The same area average with low-pass filtering (11-yr running mean) applied serves as the AMO index. We use the station-based NAO index from 1865 to 2010 (Hurrell et al. 2003; https://climatedataguide.ucar.edu/climate-data/hurrellnorth-atlantic-oscillation-nao-index-station-based).

We analyze a multimillennial (3000 years long) preindustrial control integration of a version of the Kiel Climate Model (KCM; Park et al. 2009). A list of references of published studies employing different versions of the KCM can be obtained from https://www.geomar.de/ en/research/fb1/fb1-me/research-topics/climate-modelling/ $\mathrm{kcms}$. The KCM version used here employs ECHAM5
TABLE 1. The 14 CMIP5 preindustrial control simulations used in this study. Start and end times are given as YYYYMM.

\begin{tabular}{lcc}
\hline \hline \multicolumn{1}{c}{ CMIP5 ID } & Start time & End time \\
\hline ACCESS1.0 & 030001 & 079912 \\
ACCESS1.3 & 025001 & 074912 \\
CanESM2 & 201501 & 301012 \\
CCSM4 & 080001 & 130012 \\
CESM1-BGC & 010101 & 060012 \\
CNRM-CM5 & 185001 & 269912 \\
FGOALS-s2 & 185001 & 235012 \\
GISS-E2-R & 398101 & 453012 \\
INM-CM4 & 185001 & 234912 \\
MPI-ESM-LR & 185001 & 284912 \\
MPI-ESM-MR & 185001 & 284912 \\
MPI-ESM-P & 185001 & 300512 \\
MRI-CGCM3 & 185101 & 235012 \\
NorESM1-M & 070001 & 120012 \\
\hline
\end{tabular}

(Roeckner et al. 2003) as the atmospheric component, with a horizontal resolution of T42 $\left(2.8^{\circ} \times 2.8^{\circ}\right)$ and 19 vertical levels. The ocean-sea ice component is NEMO (Madec 2008) on a $2^{\circ}$ Mercator mesh (ORCA2) horizontally, with increased meridional resolution of $0.5^{\circ}$ near the equator and 31 vertical levels. The atmosphere model is coupled to the ocean-sea ice model via OASIS (Valcke et al. 2006). A surface freshwater-flux correction is applied over the NA, which not only largely eliminates upperocean salinity biases over that region but also considerably reduces the cold NA SST bias that is common to many climate models (Park et al. 2016).

Additionally, we analyze 14 preindustrial control integrations (model length varies from 500 to 1156 years; Table 1) obtained from phase 5 of the Coupled Model Intercomparison Project (CMIP5; Taylor et al. 2012). These climate models are chosen because they provide SST, sea level pressure (SLP), barotropic streamfunction, and meridional overturning streamfunction, the four variables used in the analysis below. The data from the CMIP5 models are linearly interpolated onto a $1^{\circ} \times 1^{\circ}$ grid.

In the climate models, the NAO index is defined as the time series (PC) of the leading EOF of SLP anomalies over the North Atlantic region. The observed stationbased NAO index is selected because it is longer than the PC-based NAO index, but the two indices are highly correlated. The Niño-3 index is used to assess the influence of the eastern equatorial Pacific SST on NA SST. It is defined as the SST anomalies averaged over $5^{\circ} \mathrm{S}-$ $5^{\circ} \mathrm{N}$ and $90^{\circ}-150^{\circ} \mathrm{W}$. The SST climatology is from the NODC (Levitus) World Ocean Atlas 2018 (Locarnini et al. 2018; https://www.nodc.noaa.gov/OC5/woa18/). We use annual-mean data. All data are linearly detrended prior to the analyses except for the observed SST, which is used after subtracting an estimate of the 
global-scale external forcing signal. The detailed description of this method is given in section $2 \mathrm{~b}$. An AMOC index is obtained from the climate models and defined as the maximum of the overturning streamfunction in the Atlantic at $40^{\circ} \mathrm{N}$. Most of the overturning streamfunction indices from the CMIP5 models are taken at this latitude.

We calculate patterns of linear regression coefficients of SST on the indices described above, where the indices have been normalized by their respective standard deviation $\sigma$. Pattern correlation is the Pearson productmoment coefficient (Pearson 1895) of linear correlation between two variables. An $F$ test is used to test the significance of the regression coefficients. The Student's $t$ test and Monte Carlo simulation based on nonparametric random phase (Ebisuzaki 1997) are applied to test the significance of the correlation coefficients. Cross-spectral analysis is used to investigate the relationship between two time series. The method provides information about the relationship of two time series in the frequency domain. The cross spectrum is defined as the Fourier transform of the cross-covariance function. The cross spectrum can be decomposed into its real part (cospectrum) and its imaginary part (quadrature spectrum) from which the coherence and phase spectra are obtained. To avoid ambiguity, the squared coherence is used. The limiting value for the squared coherence for a given $\alpha$ (e.g., $\alpha=0.05$ corresponds to a confidence level of $95 \%)$ is given by

$$
\kappa_{(1-\alpha)}^{2}=1-\alpha^{[2 /(\mathrm{DoF}-2)]} .
$$

DoF is the number of degrees of freedom determined by the choice of the smoothing window (Thompson 1979). We use the Hamming window and set the window length to 150 samples with an overlap of 80 samples (preindustrial control runs) and to 40 samples with overlap of 20 samples (observations) (e.g., von Storch and Zwiers 2001). Welch's method of overlapped averaged periodogram was applied (Welch 1967).

\section{b. Signal-to-noise maximizing EOF analysis}

We follow the method of Ting et al. (2009) that is based on historical runs with climate models to remove the globalscale external forcing signal from the SST. We chose 33 CMIP5 historical simulations (only one realization of each model) from 1850 to 2010 and the corresponding preindustrial control integrations (Table 2). In this method, a signal-to-noise maximizing EOF ( $\mathrm{S} / \mathrm{N}$ EOF) analysis is applied to the global SSTs to estimate the externally forced SST variability. We note that the CMIP5 historical runs are only used in this study to remove the external forcing trend and are not used in the subsequent analysis.
The S/N EOF method assumes that the covariance matrix of $K$ number multimodel ensemble mean $\left(\mathbf{X}_{M}\right)$ can be separated into two parts: one is the forced response $\left(\mathbf{X}_{F}\right)$ and the other the internal climate variability in the $k$ th ensemble integration $\left(\mathbf{X}_{N}^{k}\right)$ or atmospheric noise:

$$
\mathbf{X}_{M}=\mathbf{X}_{F}+\frac{1}{K} \sum_{k=1}^{K} \mathbf{X}_{N}^{k}
$$

If we apply a standard EOF method to the ensemble mean, the covariance matrix of the ensemble mean $\mathbf{C}_{M}$ consists of the covariance of the forced response $\mathbf{C}_{F}$ and that of the noise $\mathbf{C}_{N}$ :

$$
\mathbf{C}_{M}=\mathbf{C}_{F}+\frac{\mathbf{C}_{N}}{K}
$$

The standard EOF methodology is not well suited to separate the forced response from the noise. Therefore, the prewhitening procedure is applied to reduce the noise contamination in the ensemble mean. This procedure involves a transformation of the covariance matrix. That is, the covariance matrix is diagonalized:

$$
\mathbf{F}^{\mathrm{T}} \mathbf{C}_{N} \mathbf{F}=K \mathbf{I},
$$

where $\mathbf{F}$ is the prewhitening operator and $\mathbf{I}$ is the identity matrix. If prewhitening is applied, the eigenvectors of the prewhitened $\mathbf{C}_{M}$ will be identical to those of the prewhitened $\mathbf{C}_{F}$. The noise covariance matrix $\mathbf{C}_{N}$ is estimated from the preindustrial control runs which, by definition, only yield the internal variability of the system. We then perform the singular value decomposition (SVD) of $\mathbf{C}_{N}$ :

$$
\mathbf{C}_{N}=\mathbf{E}_{N} \boldsymbol{\Lambda}_{N} \mathbf{P}_{N}^{\mathrm{T}},
$$

where $\mathbf{E}_{N}$ represents the eigenvectors matrix of $\mathbf{C}_{N}$ and $\boldsymbol{\Lambda}_{N}$ is the diagonal matrix of the square root of the corresponding eigenvalues. The prewhitening of the ensemble mean can be expressed as

$$
\mathbf{X}_{M}^{\prime}=\mathbf{F}^{\mathrm{T}} \mathbf{X}_{M}=\sqrt{K} \boldsymbol{\Lambda}_{N}^{-1} \mathbf{E}_{N}^{\mathrm{T}} \mathbf{X}_{M} .
$$

Then an EOF analysis is performed on the transformed data matrix $\mathbf{X}_{M}^{\prime}$. It can be shown that the leading EOF has the maximum signal-to-noise ratio and the first PC represents the time evolution of the most dominant forced response (Venzke et al. 1999). The PC1 (Fig. 1a) is taken as the time series of the forced SST response and the internal (unforced) components of the SST indices obtained by subtracting the PC1. 
TABLE 2. The 33 CMIP5 historical (HIS) and preindustrial control (PI) simulations (with original resolution) used in the signal-to-noise maximizing EOF analysis. Start and end times are given as YYYYMM.

\begin{tabular}{|c|c|c|c|c|c|c|}
\hline CMIP5 ID & HIS start time & HIS end time & PI start time & PI end time & Atmosphere resolution & Ocean resolution \\
\hline ACCESS1.0 & 185001 & 200512 & 030001 & 079912 & $1.25^{\circ} \times 1.875^{\circ}$ & $0.3^{\circ}-1^{\circ} \times 1^{\circ}$ \\
\hline ACCESS1.3 & 185001 & 200512 & 025001 & 074912 & $1.25^{\circ} \times 1.875^{\circ}$ & $0.3^{\circ}-1^{\circ} \times 1^{\circ}$ \\
\hline BCC-CSM1.1 & 185001 & 201012 & 000101 & 050012 & $2.8^{\circ} \times 2.8^{\circ}$ & $0.3^{\circ}-1^{\circ} \times 1^{\circ}$ \\
\hline BCC-CSM1.1-m & 185001 & 201012 & 000101 & 040012 & $2.8^{\circ} \times 2.8^{\circ}$ & $0.3^{\circ}-1^{\circ} \times 1^{\circ}$ \\
\hline CanESM2 & 185001 & 200512 & 201501 & 301012 & $2.8^{\circ} \times 2.8^{\circ}$ & $0.9^{\circ} \times 1.4^{\circ}$ \\
\hline CCSM4 & 185001 & 200512 & 080001 & 130012 & $0.94^{\circ} \times 1.25^{\circ}$ & $0.27-0.5^{\circ} \times 1.1^{\circ}$ \\
\hline CESM1-BGC & 185001 & 200512 & 010101 & 060012 & $0.94^{\circ} \times 1.25^{\circ}$ & $0.3^{\circ}-1^{\circ} \times 1^{\circ}$ \\
\hline CESM1-CAM5 & 185001 & 200512 & 000101 & 031912 & $0.94^{\circ} \times 1.25^{\circ}$ & $0.3^{\circ}-1^{\circ} \times 1^{\circ}$ \\
\hline CESM1-FASTCHEM & 185001 & 200512 & 007001 & 029112 & $0.94^{\circ} \times 1.25^{\circ}$ & $0.3^{\circ}-1^{\circ} \times 1^{\circ}$ \\
\hline CESM1-WACCM & 185001 & 200512 & 009601 & 029512 & $1.9^{\circ} \times 2.5^{\circ}$ & $0.3^{\circ}-1^{\circ} \times 1^{\circ}$ \\
\hline CMCC-CESM & 185001 & 200512 & 432401 & 449312 & $3.4^{\circ} \times 3.75^{\circ}$ & $0.5^{\circ}-2^{\circ} \times 2^{\circ}$ \\
\hline CMCC-CM & 185001 & 200512 & 155001 & 187912 & $0.75^{\circ} \times 0.75^{\circ}$ & $0.5^{\circ}-2^{\circ} \times 2^{\circ}$ \\
\hline CMCC-CMS & 185001 & 200512 & 368401 & 418312 & $3.71^{\circ} \times 3.75^{\circ}$ & $0.5^{\circ}-2^{\circ} \times 2^{\circ}$ \\
\hline CNRM-CM5 & 185001 & 200512 & 185001 & 269912 & $1.4^{\circ} \times 1.4^{\circ}$ & $0.3^{\circ}-1^{\circ} \times 1^{\circ}$ \\
\hline CNRM-CM5.2 & 185001 & 200512 & 185001 & 225912 & $1.4^{\circ} \times 1.4^{\circ}$ & $1.3^{\circ} \times 1.9^{\circ}$ \\
\hline GFDL CM3 & 186001 & 200512 & 000101 & 080012 & $2^{\circ} \times 2.5^{\circ}$ & $0.3^{\circ}-1^{\circ} \times 1^{\circ}$ \\
\hline GFDL-ESM2G & 186101 & 200512 & 000101 & 050012 & $2^{\circ} \times 2.5^{\circ}$ & $0.375-0.5^{\circ} \times 1^{\circ}$ \\
\hline GISS-E2-H & 185001 & 200512 & 241001 & 294912 & $2^{\circ} \times 2.5^{\circ}$ & $0.3^{\circ}-1^{\circ} \times 1^{\circ}$ \\
\hline GISS-E2-H-CC & 185001 & 201012 & 208101 & 233112 & $2^{\circ} \times 2.5^{\circ}$ & $0.3^{\circ}-1^{\circ} \times 1^{\circ}$ \\
\hline GISS-E2-R & 185001 & 200512 & 398101 & 453012 & $2^{\circ} \times 2.5^{\circ}$ & $1^{\circ} \times 1.25^{\circ}$ \\
\hline GISS-E2-R-CC & 185001 & 201012 & 205001 & 230012 & $2^{\circ} \times 2.5^{\circ}$ & $1^{\circ} \times 1.25^{\circ}$ \\
\hline HadGEM2-CC & 185901 & 200512 & 185912 & 209912 & $1.25^{\circ} \times 1.875^{\circ}$ & $0.3^{\circ}-1^{\circ} \times 1^{\circ}$ \\
\hline HadGEM2-ES & 185901 & 200512 & 185912 & 243605 & $1.25^{\circ} \times 1.875^{\circ}$ & $0.3^{\circ}-1^{\circ} \times 1^{\circ}$ \\
\hline INM-CM4 & 185001 & 200512 & 185001 & 234912 & $1.5^{\circ} \times 2^{\circ}$ & $0.5^{\circ} \times 1^{\circ}$ \\
\hline IPSL-CM5A-LR & 185001 & 200512 & 180001 & 279912 & $1.9^{\circ} \times 3.75^{\circ}$ & $2^{\circ} \times 2^{\circ}$ \\
\hline IPSL-CM5B-LR & 185001 & 200512 & 183001 & 212912 & $1.9^{\circ} \times 3.75^{\circ}$ & $2^{\circ} \times 2^{\circ}$ \\
\hline MIROC5 & 185001 & 201012 & 200001 & 266912 & $1.4^{\circ} \times 1.4^{\circ}$ & $0.5-1.4^{\circ} \times 1.4^{\circ}$ \\
\hline MPI-ESM-LR & 185001 & 200512 & 185001 & 284912 & $1.87^{\circ} \times 1.875^{\circ}$ & $1.5^{\circ} \times 1.5^{\circ}$ \\
\hline MPI-ESM-MR & 185001 & 200512 & 185001 & 284912 & $1.87^{\circ} \times 1.875^{\circ}$ & $0.4^{\circ} \times 0.4^{\circ}$ \\
\hline MPI-ESM-P & 185001 & 200512 & 185001 & 300512 & $1.87^{\circ} \times 1.875^{\circ}$ & $1.5^{\circ} \times 1.5^{\circ}$ \\
\hline MRI-CGCM3 & 185001 & 200512 & 185101 & 235012 & $1.12^{\circ} \times 1.125^{\circ}$ & $0.5^{\circ} \times 1^{\circ}$ \\
\hline NorESM1-M & 185001 & 200512 & 070001 & 120012 & $1.9^{\circ} \times 2.5^{\circ}$ & $1^{\circ} \times 1.1^{\circ}$ \\
\hline NorESM1-ME & 185001 & 200512 & 090101 & 115212 & $1.9^{\circ} \times 2.5^{\circ}$ & $0.5^{\circ} \times 1^{\circ}$ \\
\hline
\end{tabular}

\section{Results}

\section{a. SST indices}

The external forcing component of the NASST index, as calculated by using the $\mathrm{S} / \mathrm{N}$ EOF method, is shown in Fig. 1a. We note that the forced signal calculated by applying the $\mathrm{S} / \mathrm{N}$ EOF method is rather different from a linear trend and exhibits a strong increase after 1980. Figures $1 \mathrm{~b}-\mathrm{d}$ depict some of the indices that are used in the subsequent regression analyses. The NAO index, NASST index, and AMO index calculated from observations are shown in Fig. 1b. The NAO indexes obtained from both observations and the climate models are inverted and the regression analyses are performed with these inverted indices. We depict from the KCM the NASST index, AMO index, NAO index (Fig. 1c), and AMOC index (Fig. 1d). The indices from the preindustrial control integration of the KCM are shown for the model years 2075-2235, which are chosen since this period has the highest covariance with the observed AMO index. The KCM's AMOC index exhibits pronounced multidecadal variability that is consistent with that in the KCM's AMO index.

\section{b. Regression patterns}

Figure 2 depicts the spatial SST-anomaly patterns derived from observations and the climate models, which are obtained by regressing the SSTs onto the standardized indices. The explained variances are given by the contours. The map of local SST regression coefficients on the NASST index (Fig. 1b) derived from observations (Fig. 2a) depicts the well-known basinwide positive SST anomalies over the NA, with maxima in the subpolar and tropical NA and a pronounced minimum between the two maxima in the western half of the basin. The SST-anomaly pattern derived from regression onto the AMO index, which by definition largely reflects the low-frequency SST variability, is similar but emphasizes more the subpolar anomalies (Fig. 2b). Explained 

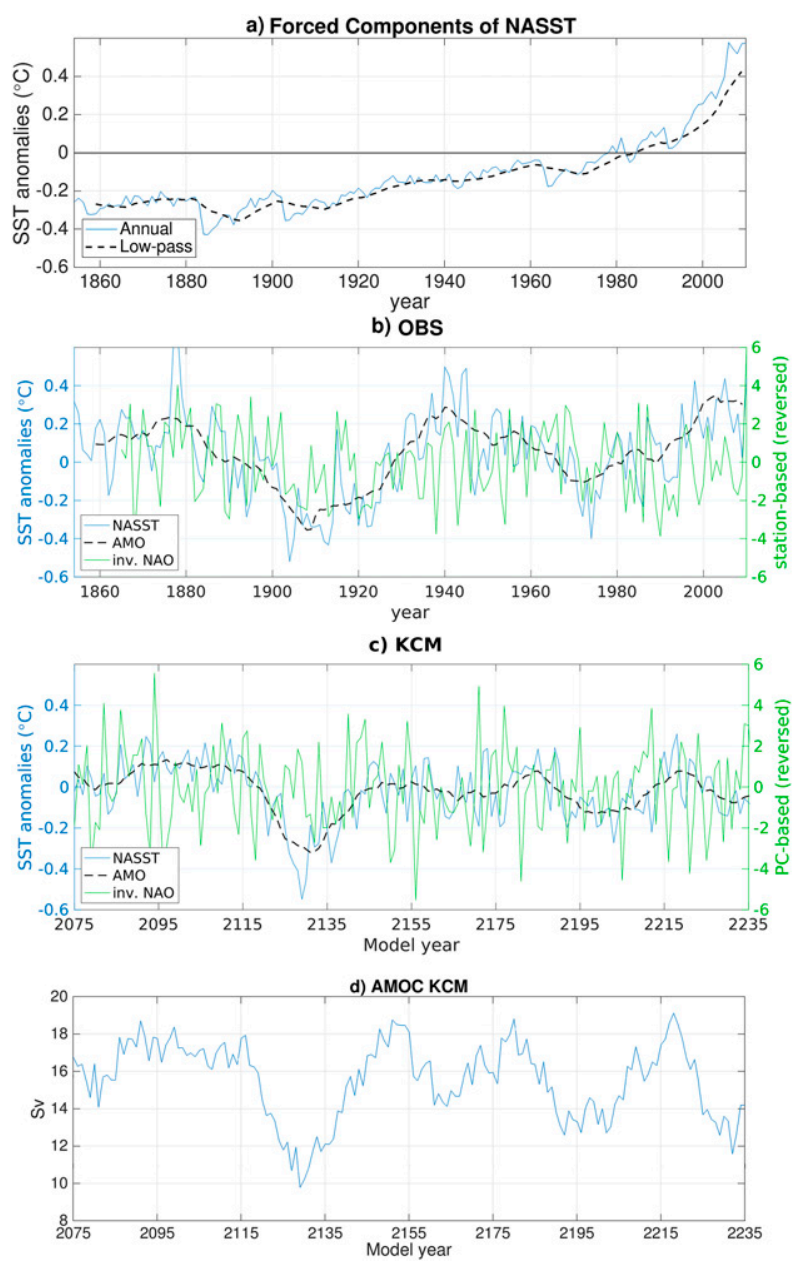

FIG. 1. (a) The externally forced component of the observed NA SST variability estimated by the S/N EOF. The blue curve indicates the forced component of observed NASST index (annual) and the black dashed curve indicates the forced component of observed AMO index (low-pass). (b) Observed indices. The blue curve indicates the NASST index 1854-2010, the black dashed curve indicates the AMO index 1859-2005, and the green curve indicates the station-based NAO index 1865-2010 (sign-reversed). (c) 160 years (model years 2075-2235, during which the covariance with the observed AMO index is maximum from the 3000-yr-long preindustrial control integration of the KCM). The blue curve indicates the NASST index, the black dashed curve indicates the AMO index, and the green curve indicates the PC-based NAO index (signreversed). (d) Same time span as in (c), but for the AMOC index in the KCM. The NASST index is defined as the annual SST anomalies over the NA averaged over the region $0^{\circ}-60^{\circ} \mathrm{N}, 7.5^{\circ}-75^{\circ} \mathrm{W}$ and the AMO index as the low-pass filtered (applying an 11-yr running mean) NASST index. The AMOC index is defined as the maximum of the overturning streamfunction in the Atlantic at $40^{\circ} \mathrm{N}$. The NAO index in observations is defined as the difference of normalized SLP between Lisbon and Reykjavik. The NAO index in the $\mathrm{KCM}$ is defined as the first PC of SLP in the NA. variances in the regression map associated with the NASST index (Fig. 2a) are larger over the tropical NA than over the subpolar NA. The explained variances over the tropical NA are considerably smaller in the regression map associated with the AMO index with a maximum of 0.2 as compared to 0.5 in the NASST-SST regression map. This is consistent with Zhang (2017) reporting that the lowfrequency SST anomalies associated with the AMO are most pronounced in the subpolar NA region while the highfrequency NA SST varies primarily in the tropical NA, adding noise to the basin-averaged index definition (Wills et al. 2019). The AMO index explains slightly less variance in SST over the subpolar NA (Fig. 2b) than the NASST index (Fig. 2a), and the regressions are slightly smaller with the exception of the Labrador Sea, where they are larger.

The regression patterns associated with the observed NASST index and the observed AMO index share some similarities with the tripolar SST-regression pattern associated with the inverted NAO index (Fig. 2c): there are two maxima, one in the subpolar and the other in the subtropical NA, and a minimum between them. However, the minimum in the regression pattern associated with the NAO index is much more pronounced being negative. The pattern correlation between the NASST index-related (Fig. 2a) and the NAOindex related SST-regression pattern (Fig. 2c) amounts to 0.71, suggesting the NASST index-related pattern is significantly influenced by SST variability that is directly related to the NAO. The relationship between the NAO and NA SST on interannual time scales is known to be local in nature and largely originating from the action of the NAO-related surface heat fluxes (Frankignoul 1985; Cayan 1992). Anomalous Ekman transport also contributes to the generation of SST anomalies over the NA (Marshall et al. 2001). The pattern correlation between the regression patterns associated with the AMO index (Fig. 2b) and the NAO index (Fig. 2c) only amounts to 0.34 , indicating that the AMO index-related pattern is less influenced by the NAO than the NASST indexrelated pattern and the ocean dynamics may be needed to explain the AMO index-related pattern.

The SST-regression pattern associated with the NASST index calculated from the preindustrial control integration of the KCM (Fig. 2d) captures the general spatial structure derived from the observations (Fig. 2a), but the KCM's SST anomalies are smaller over the tropical NA. In the observations, the explained variances in the NASST index-related pattern are larger over the tropical NA than over the subpolar NA, which also is the case in the KCM (Fig. 2d) and in the CMIP5 models' ensemble mean (see below; Fig. $2 \mathrm{~h}$ ). We note that the explained variance in most of the CMIP5 models exceeds 0.4 over limited regions of the tropical 

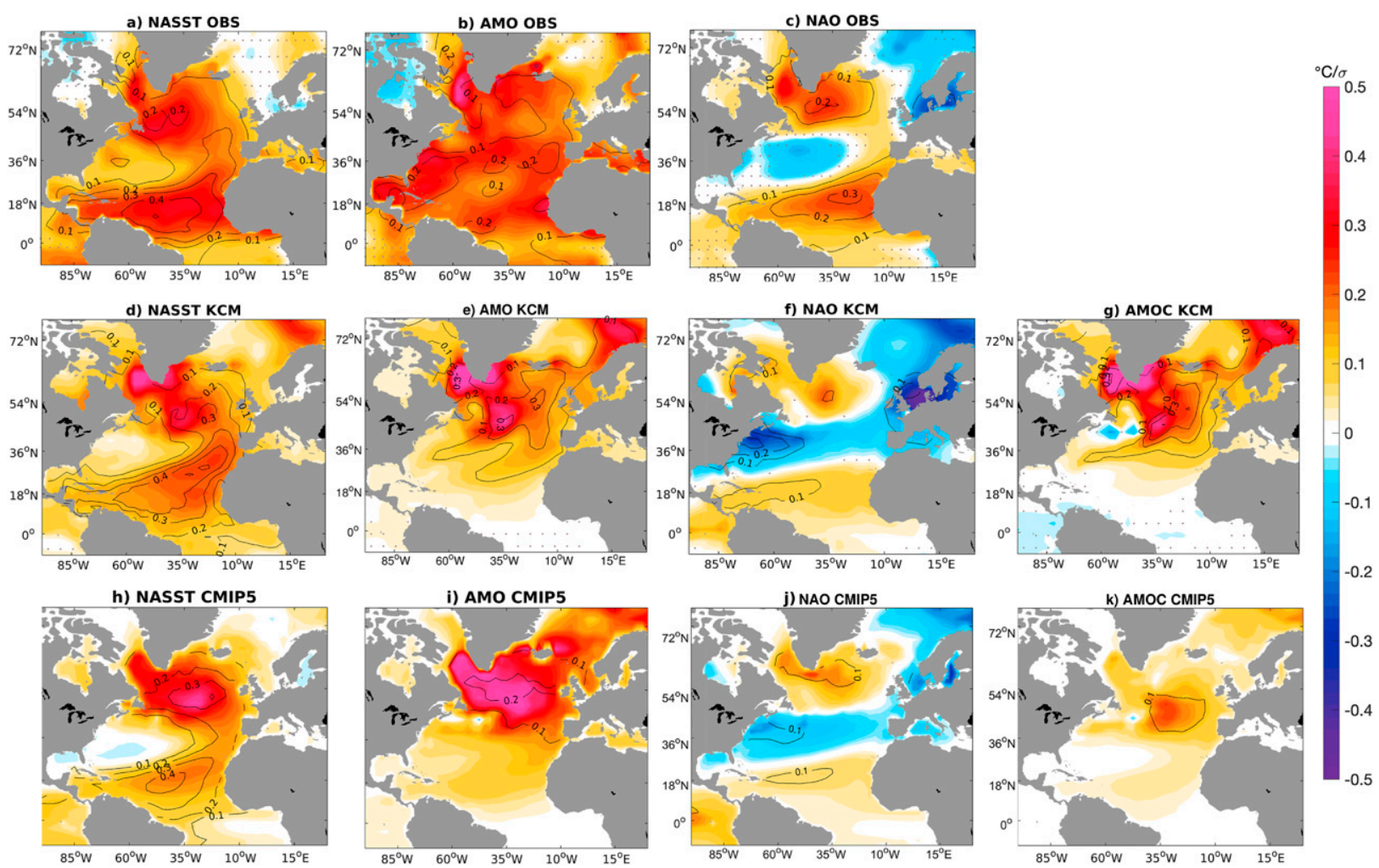

FIG. 2. (a) SST-anomaly pattern derived from regression onto the annual NASST index 1854-2010 in ERSST v5. (b) SST-anomaly pattern derived from regression onto the AMO index (low-pass filtered NASST index; see text for definition) during 1859-2005 in ERSST v5. (c) SST-anomaly pattern (sign-reversed) derived from regression onto the annual NAO index in 1865-2010. (d) As in (a), but for the regression coefficients calculated from the KCM. (e) As in (b), but for the regression coefficients calculated from the KCM. (f) As in (c), but for the regression coefficients calculated from KCM (sign-reversed). (g) SST-anomaly pattern derived from regression onto the annual AMOC index calculated from the KCM. (h) As in (a), but for the ensemble mean of regression coefficients calculated from 14 CMIP5 preindustrial control simulations. (i) As in (b), but for the ensemble mean of regression coefficients calculated from 14 CMIP5 preindustrial control simulations. (j) As in (c), but for the ensemble mean of regression coefficients calculated from 14 CMIP5 preindustrial control simulations (sign-reversed). (k) As in (g), but for the ensemble mean of regression coefficients calculated from 14 CMIP5 preindustrial control simulations. Note that the ensemble means from the CMIP5 models are calculated by averaging the regressions and explained variances from the individual models. Color shading indicates regressions; contours explaine variance. Dots means the regression is not significant at the $95 \%$ level, and the dots do not show in the CMIP5 ensemble mean. The regression coefficients correspond to a $1 \sigma$ change of the corresponding indices.

NA and can be up to 0.6 (not shown). The explained variance exceeds 0.2 over the subpolar NA in most of the CMIP5 models with values up to 0.4 in limited regions (not shown), indicating a robustness of the pattern across the CMIP5 models. When calculating the SST regression on the KCM's AMO index (Fig. 2e), tropical NA SST anomalies are largely absent south of about $30^{\circ} \mathrm{N}$. The ensemble-mean SST-regression pattern associated with the AMO index calculated from the 14 preindustrial control integrations of the CMIP5 models (Fig. 2i) is similar to that derived from the KCM in structure and magnitude. Most importantly, there are no signals over the tropical NA and significant SST anomalies with explained variances exceeding $10 \%$ are restricted to the mid- and high-latitude NA. Although the explained variances may become smaller when a multimodel ensemble average is calculated, they are only slightly smaller relative to those in the KCM, indicating a robustness of the AMO index-related pattern across the CMIP5 model ensemble. We note that there are large differences among the individual regression patterns associated with the AMO index across the CMIP5 model ensemble, but all patterns derived from the individual models exhibit relatively small SST anomalies over the tropical NA (not shown).

The regression pattern of the SST on the NAO index derived from the KCM (Fig. 2f) is consistent with that calculated from observations (Fig. 2c) featuring the tripolar SST-anomaly pattern. Compared with observations, the explained variances are smaller over the subpolar and tropical NA and larger over the midlatitude NA. The CMIP5 ensemble-mean NAO-SST 
regression map (Fig. 2j) is characterized by similar regression coefficients and explained variances compared to those from the KCM. Overall, we conclude from both the observations and the climate models that the NASST index-related SST-anomaly pattern is strongly influenced by the NAO, whereas the AMO indexrelated pattern is less influenced by the NAO and only well developed over the extratropical NA. This suggests that the ocean dynamics play an important role in the AMO.

We next investigate the role of the AMOC in the NA SST variability. Figure $2 \mathrm{~g}$ shows the SST regressions on the AMOC index calculated from the KCM. The AMOC-related SST regression pattern exhibits large positive SST anomalies over the mid- and high-latitude NA, especially over the subpolar region, but hardly any anomalies over the tropical NA. Such a structure is also observed in the ensemble-mean AMOC-related SST regression pattern derived from the CMIP5 models, but the regression coefficients and explained variances are relatively small (Fig. 2k) in comparison to the KCM. Previous studies show that the NA SST variability is not robust and varies considerably between climate models. For example, some of the CMIP5 models exhibit the largest explained variances with values of up to 0.4 over the eastern NA (not shown) whereas the ensemblemean explained variances are on the order of 0.1 (Fig. 2k). One reason for the model differences could be the cold NA SST bias observed in the vast majority of the CMIP5 models that varies among the models (Ba et al. 2014; Keenlyside et al. 2016; Zhang and Wang 2013), which will be investigated below. Although the regression patterns in the individual CMIP5 models differ from each other considerably (not shown), the ensemble-mean AMOC-related SST-anomaly pattern supports the KCM's result that the AMOC only influences the extratropical NA SST.

In the KCM, the AMO index-related SST-regression pattern (Fig. 2e) is similar to the AMOC index-related SST-regression pattern (Fig. 2g), suggesting a major influence of the AMOC on the AMO. The temporal correlation between the AMO index and the annual AMOC index amounts to 0.70 at zero lag and to 0.75 when the AMOC index leads by two years. In comparison to the AMOC index-related pattern, the SST anomalies associated with the AMO index-related pattern extend farther south straddling the equatorial NA. In the CMIP5 models, the similarity between the AMO index-related and AMOC index-related SSTregression patterns is not as striking as in the $\mathrm{KCM}$, but the CMIP5 models (Figs. 2i,k) agree with the KCM in that the largest regressions are seen over the extratropical NA and that the SST anomalies associated with the AMO index extend farther south. This suggests that the AMO index is composed of variability that additionally to the influence of the AMOC reflects tropical NA SST variability that is not related to the AMOC.

\section{c. Time scale separation of North Atlantic SST variability}

From the above regression analysis, we find that both the tropical and extratropical NA SST can be influenced by different factors. To identify these factors and their contributions over different parts of NA, another two SST indices are calculated: an extratropical NA SST index (E-NASST index hereafter) defined as the areaaveraged SST over $40^{\circ}-60^{\circ} \mathrm{N}, 7.5^{\circ}-75^{\circ} \mathrm{W}$ and a tropical NA SST index (T-NASST index hereafter) defined as the area-averaged SST over $0^{\circ}-20^{\circ} \mathrm{N}, 7.5^{\circ}-75^{\circ} \mathrm{W}$. Crossspectral analysis is performed between the NASST index and T-NASST index and between the NASST index and E-NASST index (Fig. 3). In the observations, the NASST index is highly coherent with the T-NASST index on basically all time scales but with smaller squared coherence at periods longer than decadal (Fig. 3a). The squared coherence spectrum calculated between the NASST index and the E-NASST index fluctuates considerably with time scale (Fig. 3b), with peaks on interannual, decadal, and multidecadal time scale, and pronounced minima in between. We note the increase of the squared coherence toward longer periods in Fig. 3b.

In contrast to the observations, the climate models yield a clear time scale separation. In the KCM (Figs. 3c,d), the NASST index and the T-NASST index exhibit the highest squared coherence at the interannual to decadal time scale. The NASST index and the E-NASST index exhibit the largest squared coherence at the multidecadal time scale. We note that the NASST index and the T-NASST index are almost in phase at interannual time scales. At multidecadal time scales, the NASST index slightly lags the E-NASST index. We depict the power spectra of the three KCM indices in Fig. 4. The spectrum of the NASST index (Fig. 4a) exhibits increasing power toward longer time scales and features a peak at periods of about $30-50$ years. In contrast, the spectrum of the T-NASST index exhibits largest power on short time scales and is basically flat on decadal and longer time scales (Fig. 4b). The spectrum of the E-NASST index (Fig. 4c) is steeper than that of the NASST index and also exhibits the multidecadal peak. Thus, among the three indices it is the E-NASST index that most robustly records multidecadal SST variability.

Recent studies suggest that SST anomalies in the midlatitudes can propagate into the tropics through cloud feedback (Brown et al. 2016; Yuan et al. 2016). 


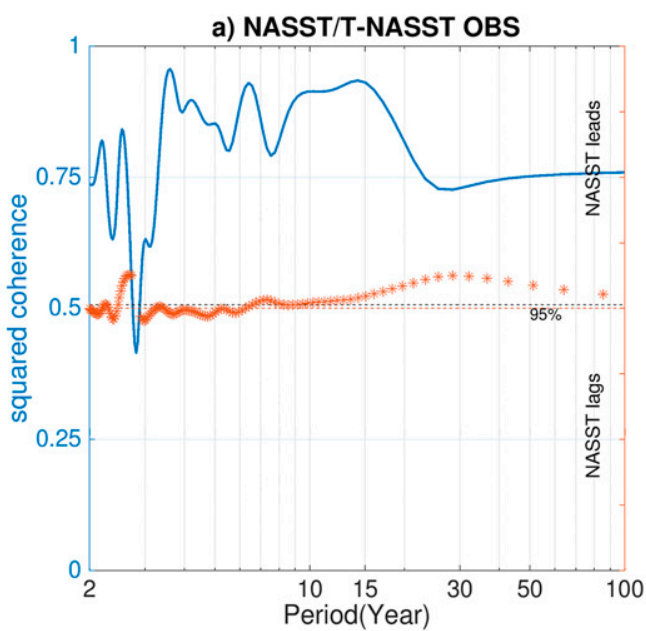

b) NASST/E-NASST OBS

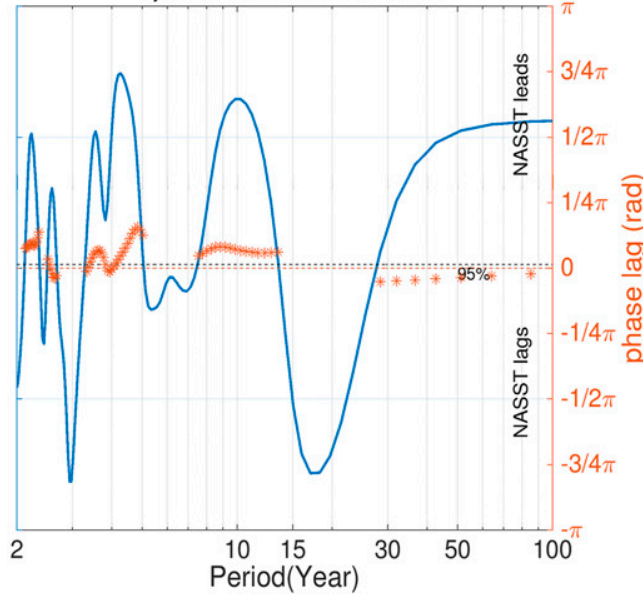

d) NASST/E-NASST KCM

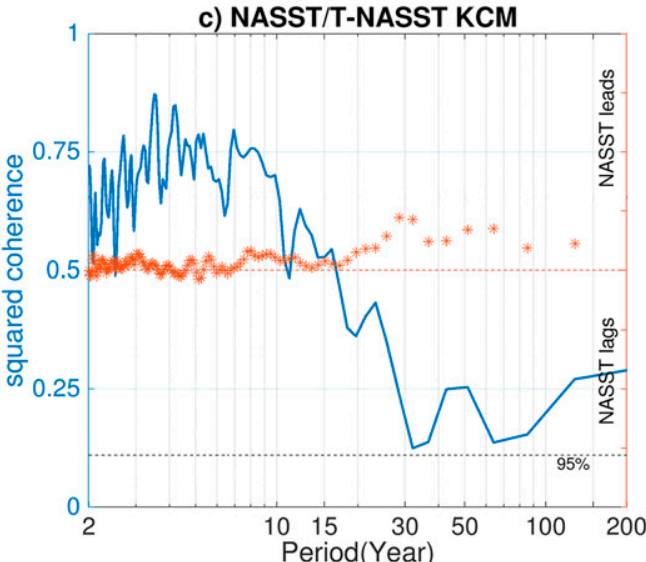

e) NASST/T-NASST CMIP5-PI

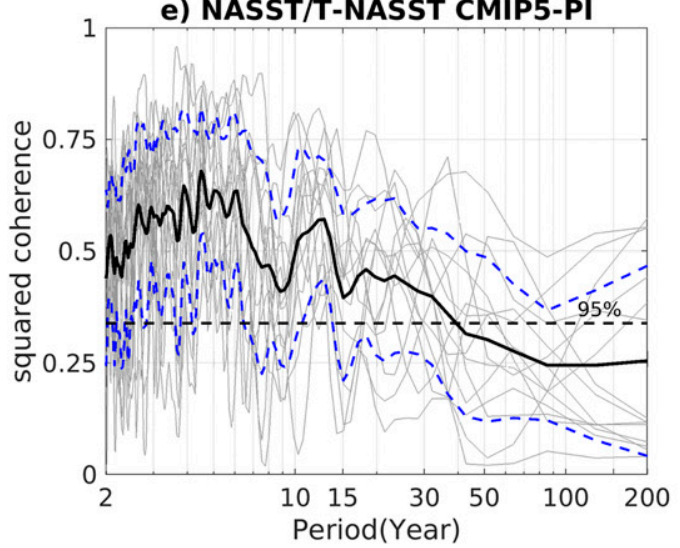

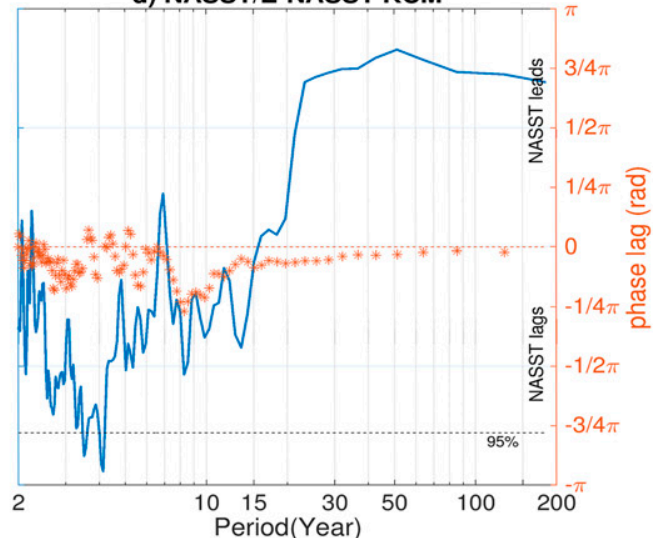

f) NASST/E-NASST CMIP5-PI

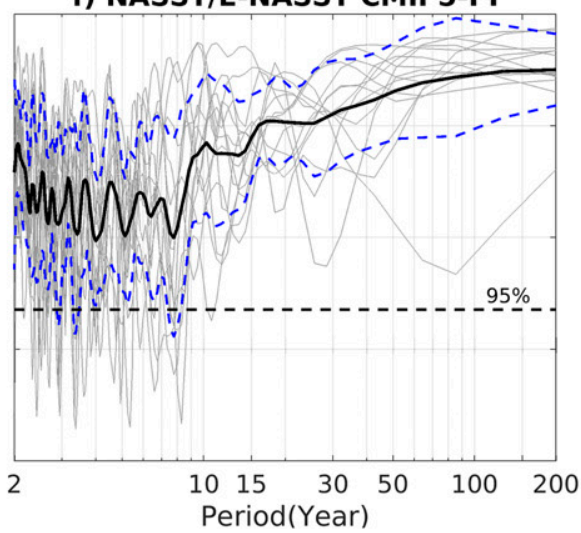

FIG. 3. Cross-spectral analysis between the NASST index and the SST indices, T-TASST $\left(0^{\circ}-20^{\circ} \mathrm{N}, 7.5^{\circ}-75^{\circ} \mathrm{W}\right)$ and E-NASST $\left(40^{\circ}-60^{\circ} \mathrm{N}, 7.5^{\circ}-75^{\circ} \mathrm{W}\right)$. Annual data are used. (a) Squared coherence (blue) and phase spectra (orange stars) between the NASST index and T-NASST index calculated from observations 1854-2010. (b) As in (a), but with the E-NASST index. (c),(d) As in (a) and (b), but for the KCM. The phase only is shown when the squared coherence exceeds the $95 \%$ confidence level (black dotted line). A phase lag of zero indicates that the two time series are in phase (orange dotted line) while a positive (negative) phase lag indicates that the NASST index leads (lags). (e) Squared coherence (gray lines) between NASST index and T-NASST index in the 14 CMIP5 preindustrial control runs; the thick black line indicates the ensemble mean of the squared coherence. (f) As in (e), but with the E-NASST index. Blue dashed curves indicate one standard deviation of the squared coherence across CMIP5 models. Black dashed curves indicate the ensemble mean 95\% confidence level of the square coherence. 

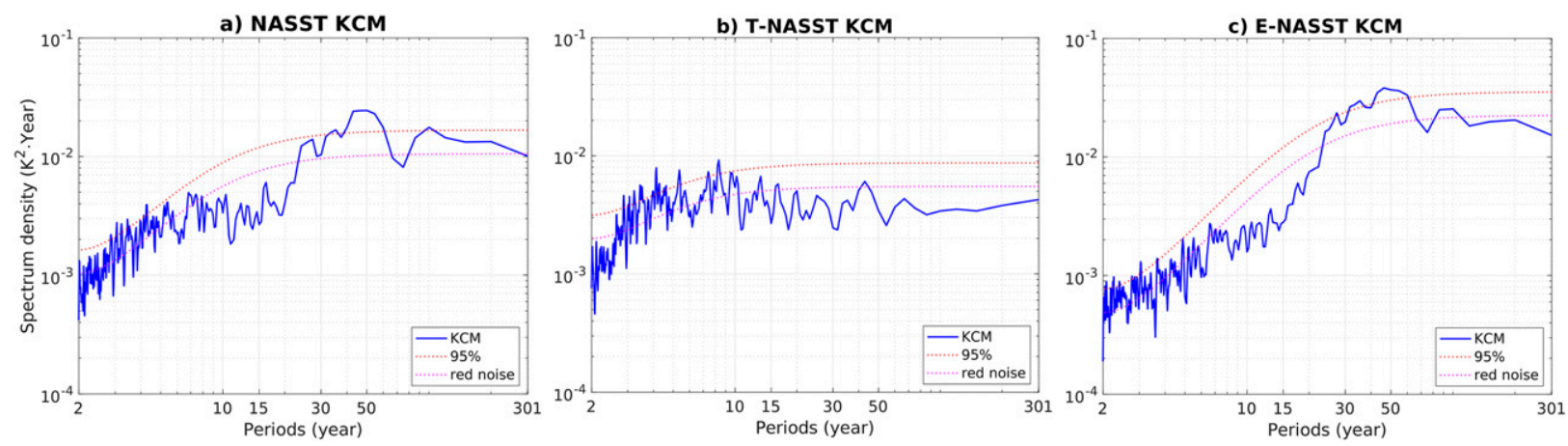

FIG. 4. (a) The power spectrum of NASST index $\left(0^{\circ}-60^{\circ} \mathrm{N}, 7.5^{\circ}-75^{\circ} \mathrm{W}\right)$ in the KCM. The power spectrum is shown in the blue curve, the dashed pink curve represents the theoretical red noise spectrum, and the dashed red curve represents the $95 \%$ confidence level. Both the $x$ axis and $y$ axis use logarithmic scales, and the $x$ axis shows the period in years. (b) As in (a), but for T-TASST $\left(0^{\circ}-20^{\circ} \mathrm{N}, 7.5^{\circ}-75^{\circ} \mathrm{W}\right)$. (c) As in (a), but for E-NASST $\left(40^{\circ}-60^{\circ} \mathrm{N}, 7.5^{\circ}-75^{\circ} \mathrm{W}\right)$.

We performed cross-spectral analysis between the T-NASST index and the E-NASST index (not shown). In both observations and in the KCM, the E-NASST index leads the T-NASST index by about $(1 / 2) \pi$ at interannual to decadal time scales but the squared coherence is far below the $95 \%$ confidence level. This suggests that the southward propagation of the SST anomalies is not a main factor contributing to the NA SST variability.

The ensemble-mean squared coherence between the NASST index, the T-NASST index, and the E-NASST index derived from the preindustrial control runs with the CMIP5 models (Figs. 3e,f) is similar to that obtained from the KCM. To visualize the ensemble spread, one standard deviation of the squared coherence and an averaged $95 \%$ confidence level (note that the length of the chosen model simulations varies) are also shown. Thus, there is a clear time scale separation in both the KCM and the CMIP5 models: the NASST index only is highly coherent with the T-NASST index on the interannual time scale. On the other hand, the NASST index only exhibits significant squared coherence with the E-NASST index on the multidecadal time scale. In conclusion, in the models the SST variability over the NA associated with the NASST index can be separated roughly into two components: a tropical component governed by interannual variability and an extratropical component governed by multidecadal variability. These results are consistent with Fig. 2 where the multidecadal NA SST variability, as expressed by the AMO index, mainly exists in the extratropical NA.

\section{d. AMOC influence on NA SST variability}

To further investigate the AMOC influence on NA SST, cross-spectral analysis is conducted between the AMOC index and the T-NASST index and between the AMOC index and the E-NASST index (Fig. 5). Since
AMOC observations are limited, we only use model data in this analysis. The results obtained the KCM (Figs. 5a,b) yield a very clear picture: the T-NASST index is unrelated to the AMOC index at all time scales, while the E-NASST index is highly coherent with the AMOC index on multidecadal time scale with the AMOC index consistently leading. The KCM's results are supported by the ensemble-mean coherence spectrum derived from the preindustrial control runs with the CMIP5 models (Figs. 5c,d). Although model spread is large, the ensemble-mean squared coherence between the AMOC index and the E-NASST index is relatively high at the multidecadal time scale. Thus, the multidecadal extratropical NA SST variability in the models has a strong link to the AMOC.

\section{e. Influence of model bias}

As noted above, the relationship between AMOC and NA SST varies among the CMIP5 models. In many models, the displacement of the North Atlantic Current in the CMIP5 models results in a cold SST bias over the extratropical NA (Drews and Greatbatch 2016, 2017). To investigate the influence of the cold SST bias on the relationship between AMOC and NA SST in the CMIP5 models, we choose the three models (CanESM2, CESM1-BGC, and CNRM-CM5) exhibiting the largest SST bias over the extratropical NA (Fig. 6a), and the three models (FGOALS-s2, GISS-E2-R, and MPIESM-MR) exhibiting the smallest SST bias over that region (Fig. 6b). Clearly, the models with the smallest SST bias show high squared coherence at the multidecadal time scale (Fig. 6c). On the other hand, the models with the largest SST bias disagree more among each other, lack high squared coherence at the multidecadal time scale, and mostly show high squared coherence on the centennial time scale (Fig. 6d). As mentioned above, we use here a freshwater-flux 

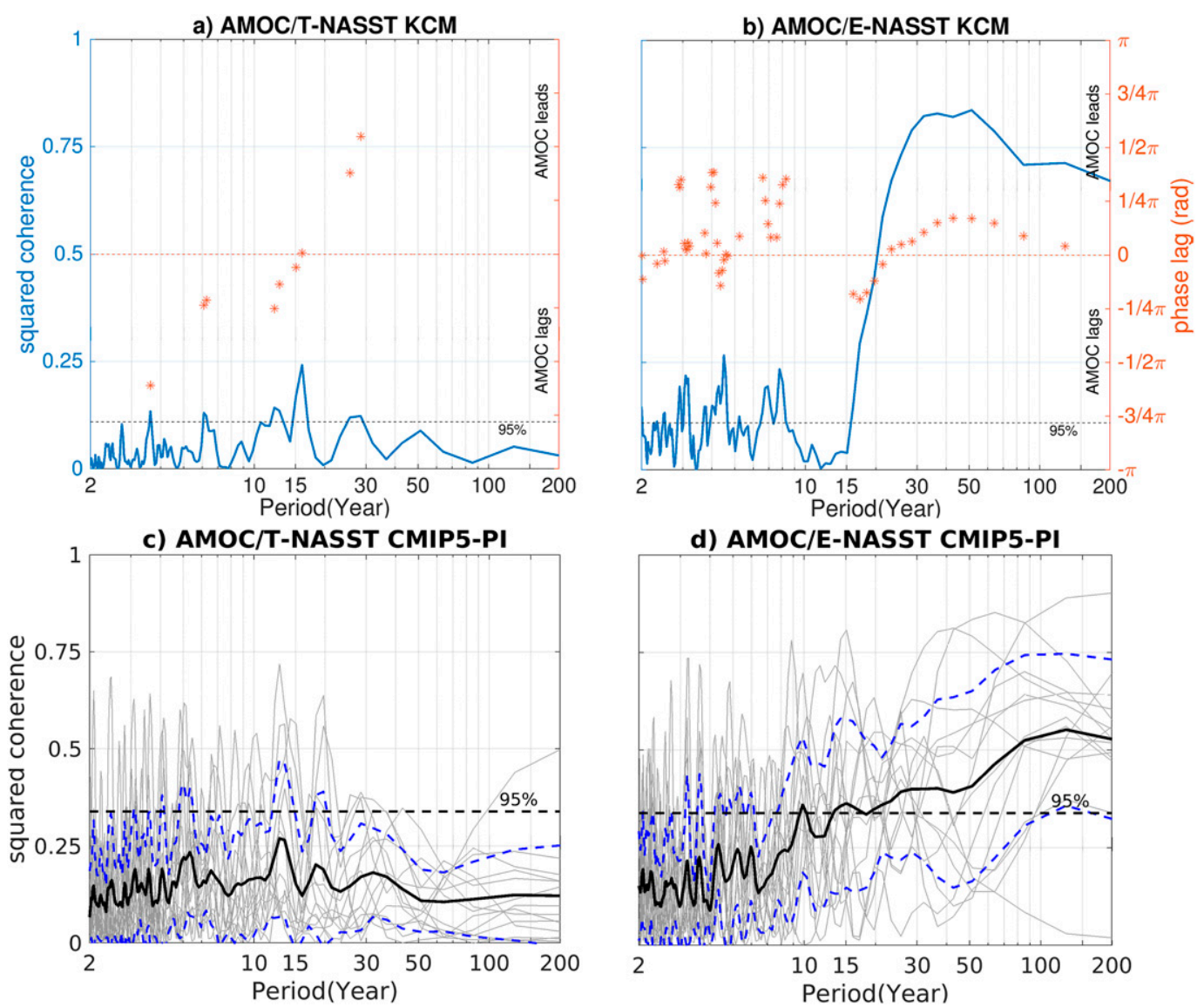

d) AMOC/E-NASST CMIP5-PI

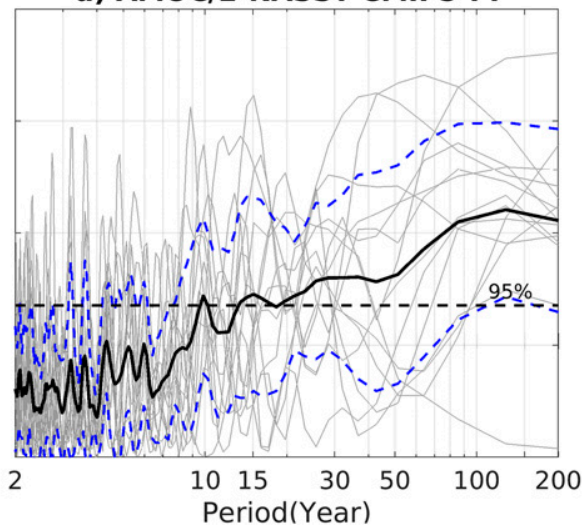

FIG. 5. Cross-spectral analysis between the AMOC index and the SST indices, T-TASST $\left(0^{\circ}-20^{\circ} \mathrm{N}, 7.5^{\circ}-75^{\circ} \mathrm{W}\right)$ and E-NASST $\left(40^{\circ}-60^{\circ} \mathrm{N}, 7.5^{\circ}-75^{\circ} \mathrm{W}\right)$. Annual data are used. (a) Squared coherence (blue) and phase spectra (orange stars) between the AMOC index and T-NASST index in the KCM. (b) As in (a), but with the E-NASST index. The phase only is shown when the squared coherence exceeds the $95 \%$ confidence level (black dotted line). A phase lag of zero indicates that the two time series are in phase (orange dotted line) while a positive (negative) phase lag indicates that the AMOC index leads (lags). (c),(d) As in (a) and (b), but for 14 CMIP5 preindustrial control runs. Blue dashed curves indicate one standard deviation of the squared coherence across CMIP5 models. Black dashed curves indicate the ensemble mean $95 \%$ level of the square coherence.

corrected KCM version with much reduced cold SST bias over the extratropical NA relative to the standard version. The corrected KCM version exhibits high squared coherence between the AMOC index and the E-NASST index at multidecadal time scale, as shown above (Fig. 5b), which is consistent with the three CMIP5 models exhibiting the smallest cold SST bias (Fig. 6c).

\section{f. Lagged NA SST response to NAO variability}

The NAO is another important factor that contributes to the NA SST variability. According to the discussion around Fig. 2, the NAO can induce a tripolar SSTanomaly pattern via anomalous surface heat fluxes. Cross-spectral analysis between the NAO index and the SST indices, T-NASST and E-NASST, is performed (Fig. 7). It should be mentioned that the NAO index used in the two cross-spectral analyses has not been inverted, because we wish to show the influence of the positive NAO phase on the NA SST variability. The results obtained from the observations and the climate models differ considerably. Considering the NAO index and the T-NASST index, we find in observations an enhanced squared coherence and an out-of-phase relationship at the biennial period (Fig. 7a). Additionally, there is a pronounced peak of the squared coherence between the NAO index and the T-NASST index with an out-of-phase relationship at a period of 15 years (Fig. 7a). Neither in the KCM (Fig. 7c) nor in the CMIP5 models (in the ensemble mean; Fig. 7e) is such a decadal peak found. We note that in the KCM's preindustrial control run the spectrum of the NAO index is consistent with white noise (not shown).

We next consider the relationship between the NAO index and the E-NASST index (Figs. 7b,d,f). Previous 
a) Small SST Bias-PI

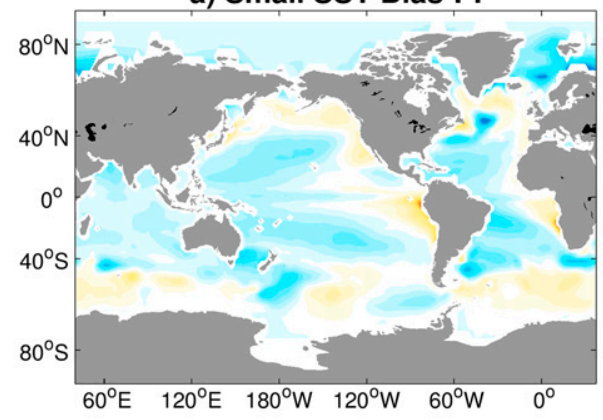

c) AMOC/E-NASST PI small

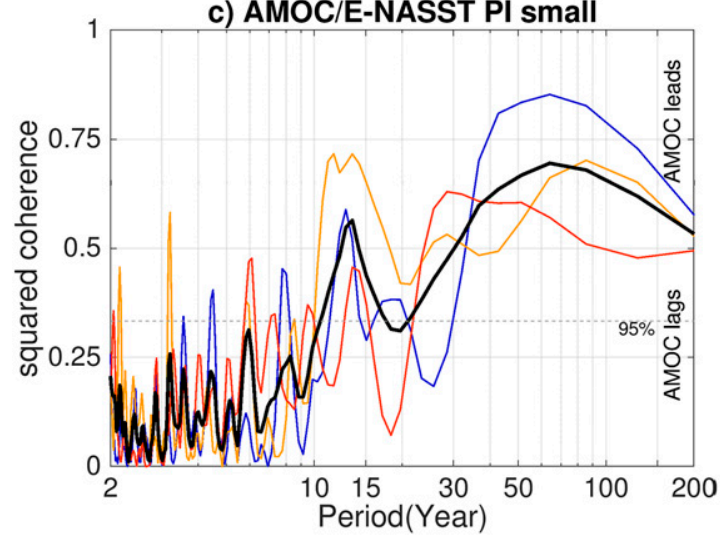

b) Large SST Bias-PI

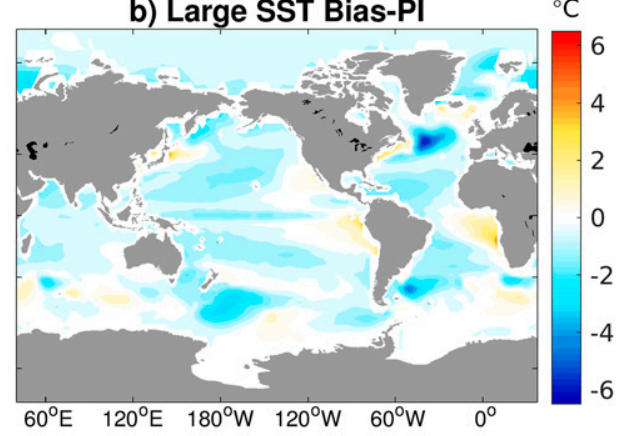

d) AMOC/E-NASST PI large

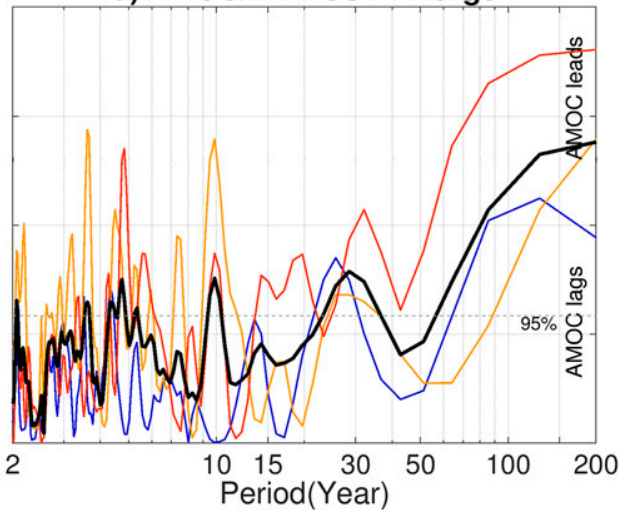

FIG. 6. Ensemble-mean long-term annual SST bias relative to Levitus climatology calculated from a selection of preindustrial control simulations with CMIP5 models: (a) mean SST bias from the three CMIP5 models (FGOALSs2, GISS-E2-R, and MPI-ESM-MR) exhibiting the smallest SST bias over the North Atlantic and (b) mean SST bias from the three CMIP5 models (CanESM2, CESM1-BGC, and CNRM-CM5) exhibiting the largest SST bias over the North Atlantic. (c) Squared coherence between the AMOC index and the E-NASST index in the CMIP5 models with the smallest SST bias (colored lines) and the ensemble mean of these models (thick black line). A mean 95\% confidence level is shown as the gray dashed line. (d) As in (c), but for the CMIP5 models with the largest SST bias. The phase is not shown in (c) and (d).

work by Eden and Willebrand (2001) suggested a twotime scale response of the NA ocean circulation to NAO variability that could influence SST over the extratropical NA: a fast barotropic response due to anomalous Ekman transport (intraseasonal time scale) and a delayed baroclinic response (time scale of 6-8 years) due to enhanced meridional overturning and a spinup of the subpolar gyre. The slow response is somewhat suggested by the observations, as the NAO index leads the E-NASST index at the multidecadal time scale (not shown), but the instrumental record is short and squared coherence at the multidecadal time scale, though enhanced, does not exceed the $95 \%$ confidence level (Fig. 7b). The fast response is not resolved by annual mean data.

The slow response is clearly simulated by the $\mathrm{KCM}$, as suggested by the high squared coherence between the NAO index and the E-NASST index (Fig. 7d) as well as the high squared coherence between the AMOC index and the E-NASST index (Fig. 5b). In the KCM, the NAO index leads the E-NASST index by about $(1 / 4) \pi$, amounting to about $6-8$ years. This time lag is consistent with that derived from the ocean model simulations in Eden and Willebrand (2001). Due to the large spread, the ensemble-mean squared coherences derived from the CMIP5 models (Fig. 7f) are insignificant at all time scales.

We conclude from the above analysis that the SSTanomaly pattern associated with the North Atlantic basin-averaged SST index (NASST index), which is based on annual data, lumps together tropical and extratropical SST variability although the two are related to different mechanisms. Climate models suggest that the extratropical part of the SST-anomaly pattern associated with the NASST index is linked to multidecadal AMOC variability. On the other hand, the models suggest that the tropical part is governed by interannual SST variability that is unrelated to the AMOC. The AMO index, defined as the low-pass filtered NASST index, only tracks extratropical NA SST variability in the climate models, although the 


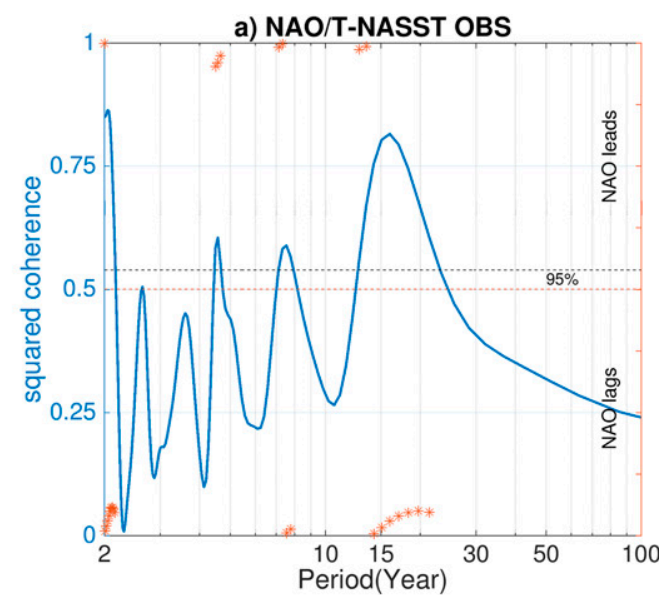

c) NAO/T-NASST KCM

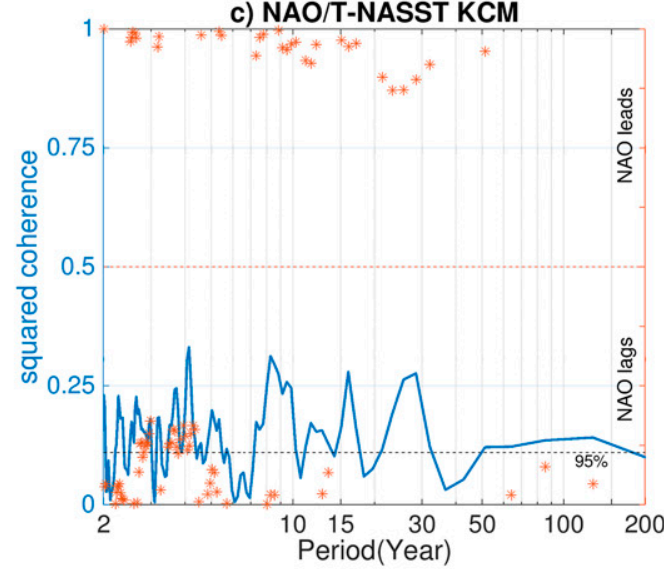

e) NAO/T-NASST CMIP5-PI

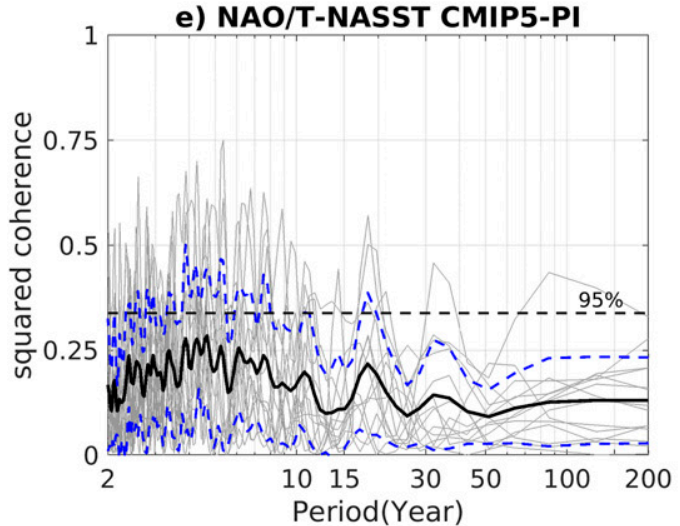

b) NAO/E-NASST OBS

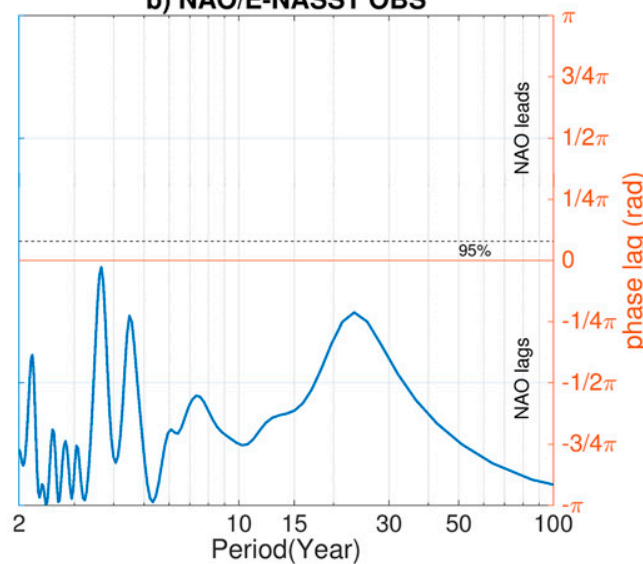

d) NAO/E-NASST KCM

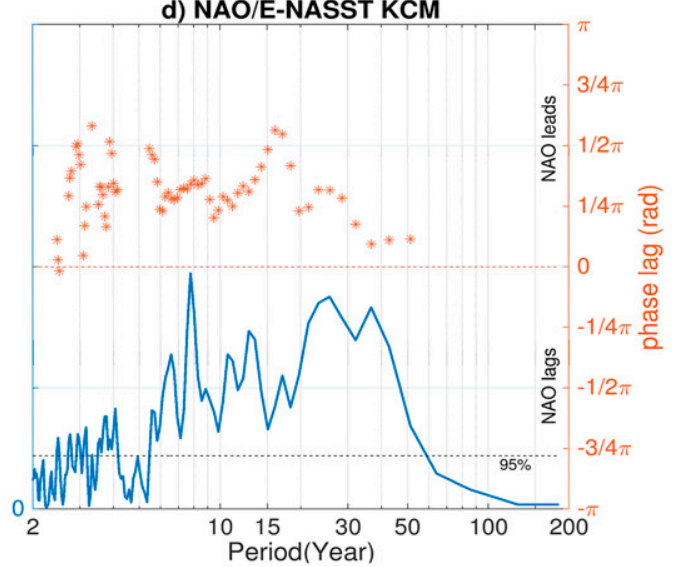

f) NAO/E-NASST CMIP5-PI

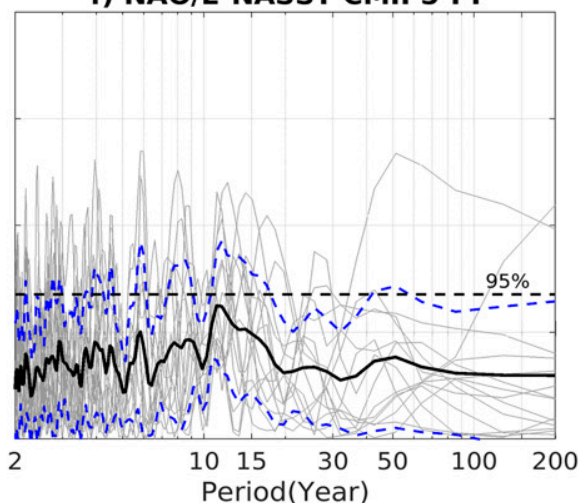

FIG. 7. Cross-spectral analysis between the NAO index and the SST indices, T-NASST $\left(0^{\circ}-20^{\circ} \mathrm{N}, 7.5^{\circ}-75^{\circ} \mathrm{W}\right)$ and E-NASST $\left(40^{\circ}-60^{\circ} \mathrm{N}, 7.5^{\circ}-75^{\circ} \mathrm{W}\right)$. Annual data are used. (a) Squared coherence (blue) and phase spectra (orange stars) between the NAO index and T-NASST index calculated from observations 1865-2010. (b) As in (a), but with the E-NASST index. (c),(d) As in (a) and (b), but for the KCM. The phase only is shown when the squared coherence exceeds the $95 \%$ confidence level (black dotted line). A phase lag of zero indicates that the two time series are in phase (orange dotted line) while a positive (negative) phase lag indicates that the NAO index leads (lags). (e),(f) Squared coherence (gray lines) between NAO index and T-NASST index in the 14 CMIP5 preindustrial control runs; the thick black line indicates the ensemble mean of the squared coherences. Blue dashed curves indicate one standard deviation of the squared coherence across CMIP5 models. Black dashed curves indicate the ensemble mean $95 \%$ confidence level of the square coherence. 

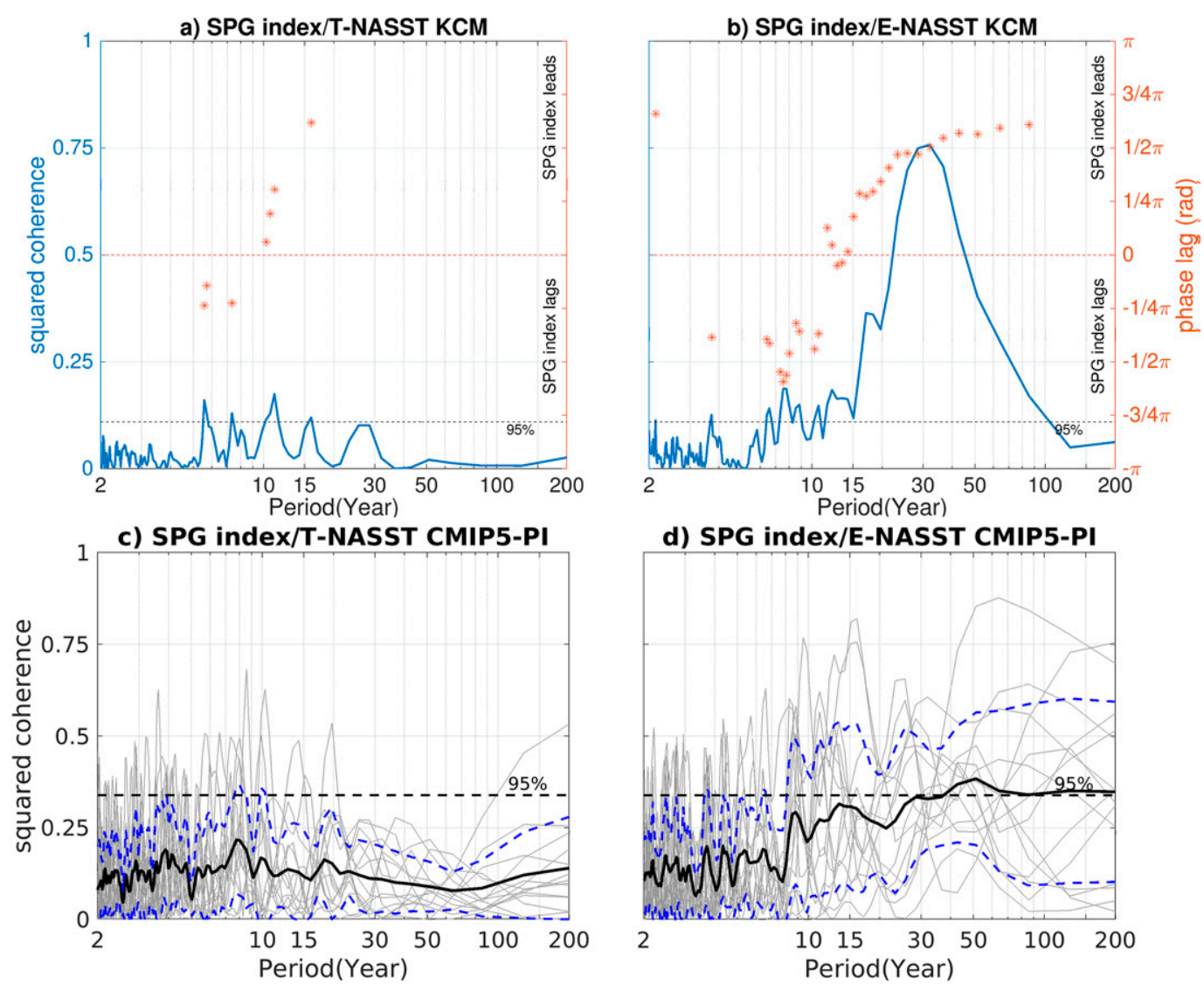

d) SPG index/E-NASST CMIP5-PI

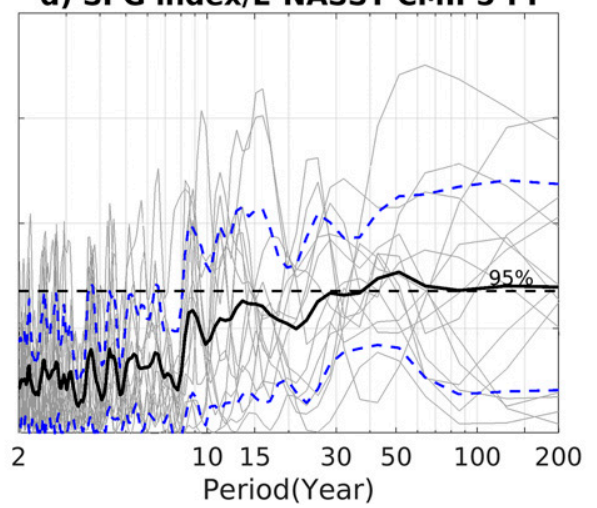

FIG. 8. Cross-spectral analysis between the SPG index and the SST indices, T-TASST $\left(0^{\circ}-20^{\circ} \mathrm{N}, 7.5^{\circ}-75^{\circ} \mathrm{W}\right)$ and E-NASST $\left(40^{\circ}-60^{\circ} \mathrm{N}, 7.5^{\circ}-75^{\circ} \mathrm{W}\right)$. Annual data are used. (a) Squared coherence (blue) and phase spectra (orange stars) between the SPG index and T-NASST index in the KCM. (b) As in (a), but with the E-NASST index. The phase only is shown when the squared coherence exceeds the $95 \%$ confidence level (black dotted line). A phase lag of zero indicates that the two time series are in phase (orange dotted line) while a positive (negative) phase lag indicates that the SPG index leads (lags). (c),(d) As in (a) and(b), but for 14 CMIP5 preindustrial control runs. Blue dashed curves indicate one standard deviation of the squared coherence across CMIP5 models. Black dashed curves indicate the ensemble mean $95 \%$ confidence level of the square coherence.

extratropical NA area is small in comparison to the full NA area over which the AMO index is defined. In the climate models, the SST variability associated with the AMO index is clearly linked to the AMOC. This link is very clear in the KCM. The CMIP5 models considerably differ among each other, which could be due to varying model biases over the NA (Fig. 6), but the ensemblemean results also point toward the picture suggested by the KCM. The overturning observations at $26^{\circ} \mathrm{N}$ only starting in 2004 are too limited to draw robust conclusions about the connection between the AMO and the AMOC.

\section{g. SPG influence on NA SST}

Eden and Willebrand (2001) suggested that the delayed ocean circulation response to the NAO variability not only is related to the AMOC but also could be caused by an adjustment of the subpolar gyre. To investigate the importance of the subpolar gyre for the NA SST variability we compute from the climate models a subpolar gyre index (SPG index) defined as the inverted area average of the barotropic streamfunction over the region $50^{\circ}-58^{\circ} \mathrm{N}, 26^{\circ}-42^{\circ} \mathrm{W}$. The SPG index calculated in this way is highly correlated with the PC1 of EOF1 calculated from the barotropic streamfunction over the same region, with a correlation coefficient of up to 0.92 . The cross-spectral analysis results between the SPG index and the SST indices, T-NASST and E-NASST, are shown in Fig. 8. In the KCM, the T-NASST index is not strongly linked to the SPG index on any time scale (Fig. 8a), which is consistent with the CMIP5 preindustrial control runs (Fig. 8c). The E-NASST index, on the other hand, exhibits highly significant squared coherence with the SPG index in the $\mathrm{KCM}$ on the 

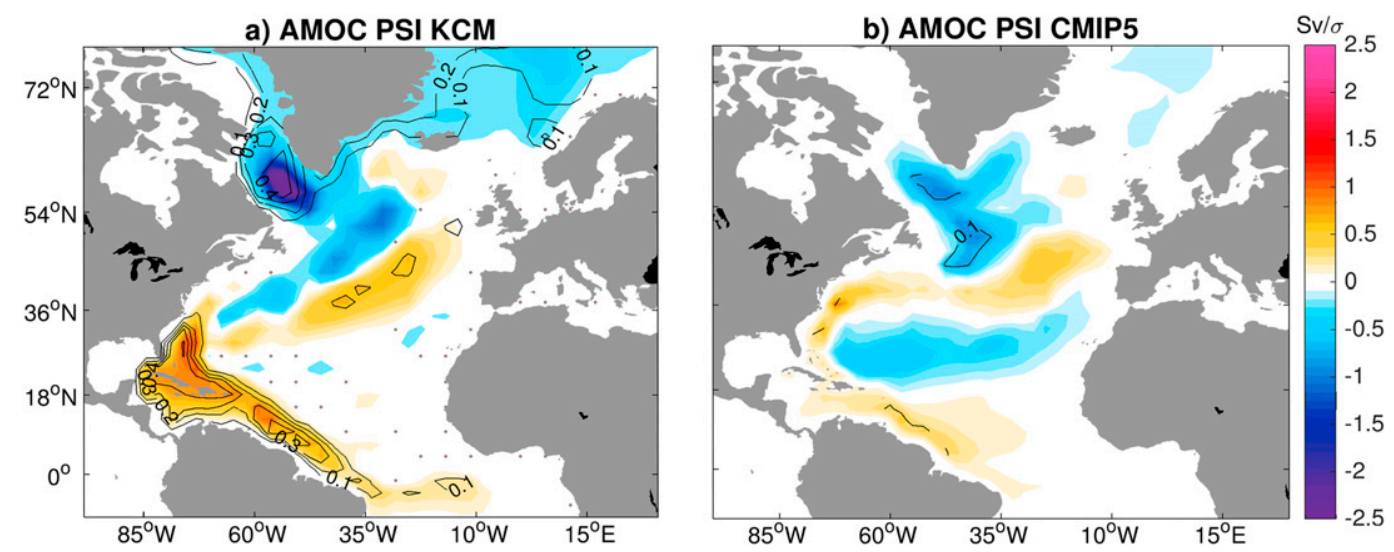

FIG. 9. (a) Barotropic streamfunction (PSI) anomalies pattern derived from regression onto the annual AMOC index calculated from the KCM. (b) As in (a), but calculated by the ensemble mean of 14 CMIP5 preindustrial control simulations. Note that the ensemble mean from the CMIP5 models is calculated by averaging the regressions and explained variances from the individual models. Color shading indicates regressions; contours explain variance. Dots mean the regression is not significant at $95 \%$ confidence level, and the dots do not show in the CMIP5 ensemble mean. The regression coefficients correspond to a $1 \sigma$ change of the corresponding indices.

multidecadal time scale, with the SPG index leading by several years (Fig. 8b). The CMIP5 models somewhat support this result, as expressed by the enhanced ensemble-mean squared coherence between the E-NASST index and the SPG index at multidecadal time scale (Fig. 8d), but the ensemble-mean squared coherence is not as large as in the KCM. We note that in the KCM (Fig. 9a) and also on average in the CMIP5 models (Fig. 9b), a stronger AMOC is associated with an enhanced subpolar gyre. This is demonstrated by the regressions of the barotropic streamfunction (PSI) on the AMOC index. The strengthened subpolar gyre will enhance the northward heat transport into the extratropical NA, which leads to warmer SSTs over the subpolar NA and at least partly explains the relationship between the SPG index and the E-NASST index observed in the models (Figs. 8b,d).

\section{h. Tropical Pacific influence on NA SST variability}

Previous studies have shown that the tropical Atlantic SST variability is strongly related to local trade wind changes (e.g., Carton et al. 1996; Kushnir et al. 2002) and the wind-evaporation-SST (WES) feedback (Xie and Philander 1994). This picture is supported by the local correlation coefficients between SST and surface wind speed anomalies calculated from the KCM. The correlations between the two quantities over the tropical NA are relatively large and typically amount to about -0.6 in the region $15^{\circ}-30^{\circ} \mathrm{N}$ (not shown). Besides the locally generated surface wind variability, ENSO has been shown to exert robust remote impacts on the SST over the tropical NA (Enfield and Mayer 1997). To study the ENSO influence on NA SST, we use the Niño-3 index and perform cross-spectral analysis with the T-NASST index and the E-NASST index. Figures 10a and 10b show the results derived from the observations. ENSO is highly coherent with T-NASST at interannual time scales, with ENSO leading (Fig. 10a). We note the large peak around a period of 15 years that also is seen in the coherence spectrum computed from the NAO index and the T-NASST index (Fig. 7a). The peak at interannual time scales (Fig. 10a) can also be found in the KCM (Fig. 10c) and in the ensemble-mean coherence spectrum calculated from the CMIP5 models (Fig. 10e).

The relationship between the Niño-3 index and the E-NASST index differs between the observations and the climate models. In the observations, there is statistically significant squared coherence at interannual time scales. This is the case neither in the coherence spectrum calculated from the KCM (Fig. 10d) nor in the ensemble-mean coherence spectrum calculated from the CMIP5 models (Fig. 10f). We conclude that the remote forcing by ENSO is an important component of tropical NA SST variability. It remains unclear to which extent ENSO also drives extratropical NA SST variability. The observations suggest some influence, which, however, is not supported by the climate models investigated in this study.

\section{Summary and discussion}

In this study, observations and climate model simulations are analyzed to aid interpretation of the North Atlantic averaged sea surface temperature (NASST). We investigate two indices: an annual index, termed the NASST index, and a low-pass filtered index that serves 


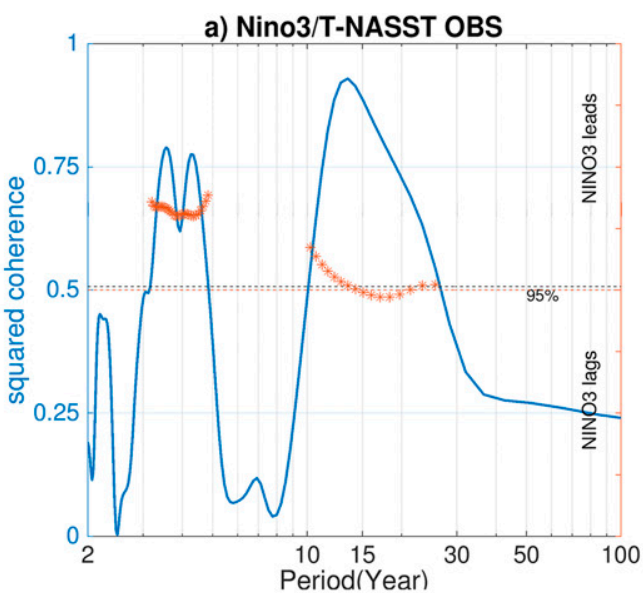

c) Nino3/T-NASST KCM
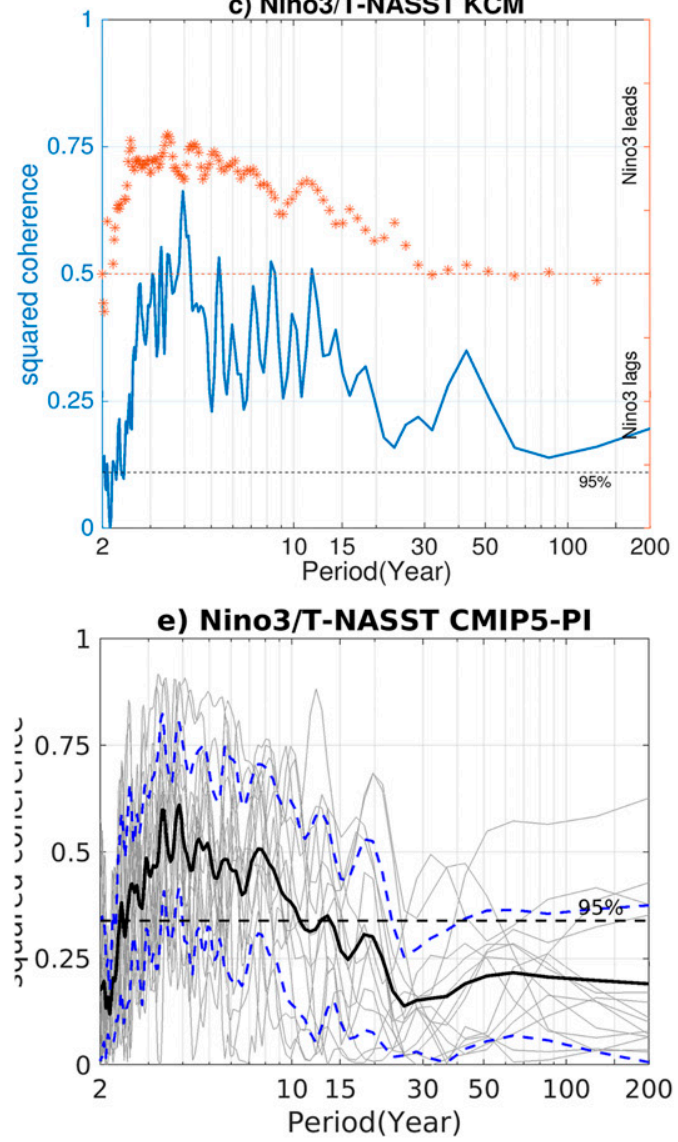

b) Nino3/E-NASST OBS

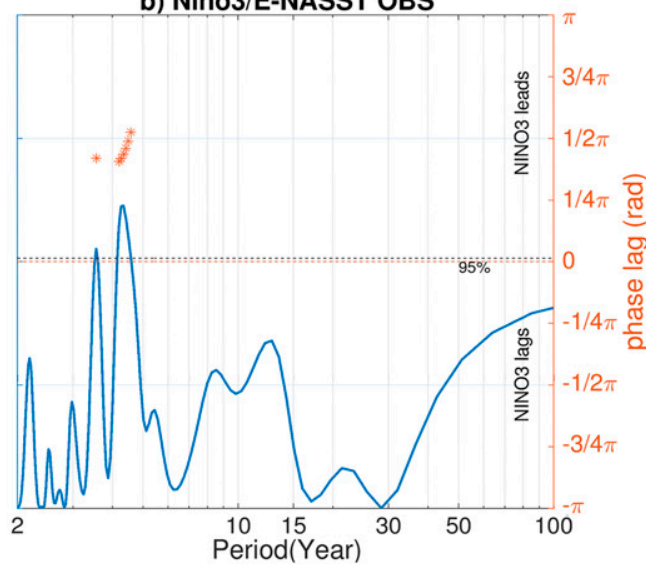

d) Nino3/E-NASST KCM

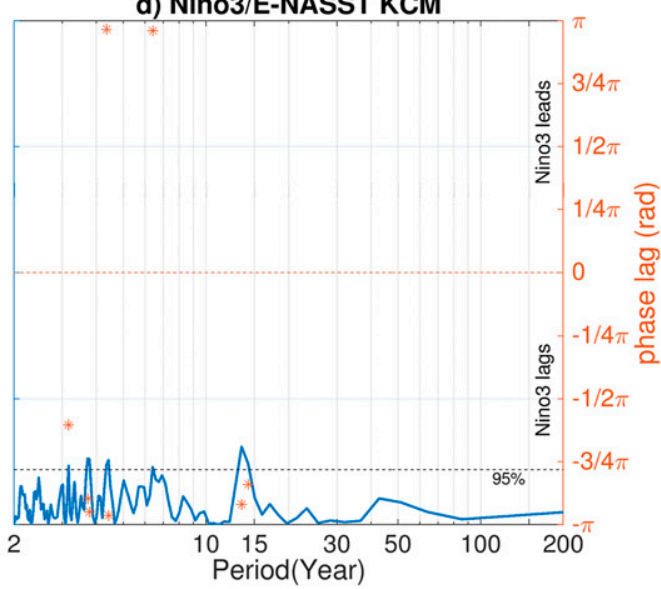

f) Nino3/E-NASST CMIP5-PI

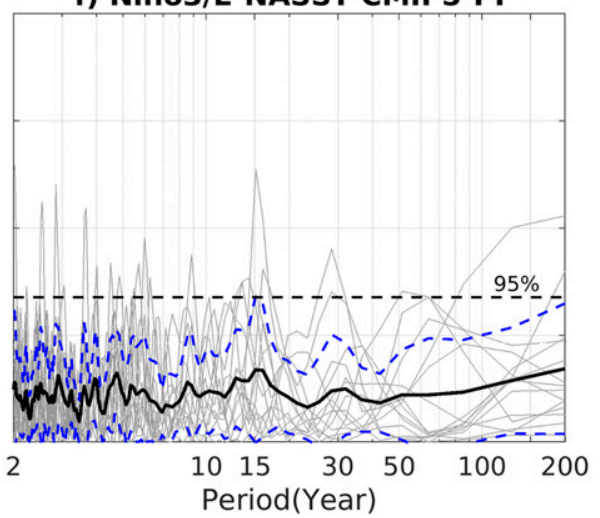

FIG. 10. Cross-spectral analysis between the Niño- 3 index and the SST indices, T-TASST $\left(0^{\circ}-20^{\circ} \mathrm{N}, 7.5^{\circ}-75^{\circ} \mathrm{W}\right)$ and E-NASST $\left(40^{\circ}-60^{\circ} \mathrm{N}, 7.5^{\circ}-75^{\circ} \mathrm{W}\right)$. Annual data are used. (a) Squared coherence (blue) and phase spectra (orange stars) between the NASST index and T-NASST index calculated from observations 1854-2010. (b) As in (a), but with the E-NASST index. (c),(d) As in (a) and (b), but for the KCM. The phase only is shown when the squared coherence exceeds the $95 \%$ confidence level (black dotted line). A phase lag of zero indicates that the two time series are in phase (orange dotted line) while a positive (negative) phase lag indicates that the Niño-3 index leads (lags). (e) Squared coherence (gray lines) between the Niño-3 and T-NASST index in the 14 CMIP5 preindustrial control runs; the thick black line indicates the ensemble mean of the squared coherence. (f) As in (e), but with the E-NASST index. Blue dashed curves indicate one standard deviation of the squared coherence across CMIP5 models. Black dashed curves indicate the mean 95\% confidence level of the square coherence. 
as the AMO index. The SST-anomaly pattern associated with the observed AMO index is similar to the pattern associated with the observed NASST index but highlights the extratropical SST variability. Moreover, in observations, the NASST index-related pattern is significantly influenced by SST variability that is directly related to the NAO, whereas the AMO index-related pattern is much less influenced by the NAO. In observations there is some weak evidence for the NAO leading the extratropical NA SST at the multidecadal time scale, suggesting a delayed ocean circulation influence on NA SST.

By using cross-spectral analysis, we argue that the two basin-averaged NA SST indices, the NASST index and the AMO index, are not appropriate to address the mechanisms of NA SST variability because relevant mechanisms operate on different time scales and over different regions of the NA. We thus conclude that neither NASST nor AMO constitutes a physical mode with a well-defined pattern and period and unique mechanism. Since observations are limited and to obtain further insight into the origin of NA SST variability, heavy use was made of data from preindustrial control integrations of the Kiel Climate Model (KCM) and of models participating in phase 5 of the Coupled Model Intercomparison Project (CMIP5). In the models, consistent with observations, the NASST index, is shown to be composed of SST variability originating from different factors: the NAO, AMOC, SPG, and ENSO. The SST variability associated with the AMOC is restricted to the mid- and high-latitude NA and the multidecadal time scale, consistent with previous studies using different climate models (Delworth and Zeng 2016; Delworth et al. 2016; Zhang 2017; Wills et al. 2019). In line with this result, the AMO-related SST-anomaly pattern is similar to the AMOC-related SST-anomaly pattern in the models.

It is known from observations that the NAO plays an important role in North Atlantic SST variability on different time scales, especially on intraseasonal to interannual time scales. In the KCM, we also find a clear link of the extratropical NA SST to the NAO at the multidecadal time scale. The connection between the NAO and the extratropical NA SST in the KCM is through the SPG and the AMOC. The spread among the CMIP5 models is so large that in the ensemble mean, there is only a weak connection between the NAO and the extratropical NA SST at any time scale. In the KCM as well as in the CMIP5 models, SPG and AMOC variability is significantly linked at the multidecadal time scale. An SPG influence on extratropical NA SST on intermediate time scale has been previously suggested in several studies (e.g., Curry and McCartney 2001; Eden and Jung 2001; Sun et al. 2015; Reintges et al. 2016; Nigam et al. 2018; Martin et al. 2019; Wills et al. 2019) and there is some weak evidence for the link in the climate models investigated in this study.

One limitation is the lack of sufficiently long instrumental observations, which inhibits, for example, investigating the influence of the AMOC on NA SST at time scales longer than interannual. Moreover, the SST observations are not long enough to estimate robust statistics and links of the NASST and AMO indices to the SST in different regions of the NA. For this reason, we are heavily relying on climate models that are known to suffer from large SST biases over the NA (e.g., Zhang and Zhao 2015). In particular, most CMIP5 models exhibit a large cold SST bias of several degrees Celsius over the northwest corner region of the NA. We show that the cold bias has a major influence on the origin of multidecadal NA SST variability. CMIP5 models with a small bias exhibit a robust link between the AMOC and extratropical NA SST at the multidecadal time scale, while the relationship is less robust in the models exhibiting a large cold bias.

The cold bias problem is the major reason why we made extensive use of a freshwater flux-corrected version of the KCM that exhibits relatively little SST bias over the tropical and extratropical NA. The corrected $\mathrm{KCM}$ simulates enhanced ocean dynamics in the NA in comparison to the uncorrected version exhibiting large SST biases (Park et al. 2016), such as more realistic SPG and deep convection sites. Consistent with the CMIP5 models, the corrected $\mathrm{KCM}$ simulates a pronounced link between AMOC and extratropical NA SST on multidecadal time scales, while this link is much weaker in the uncorrected KCM (not shown). One implication of this result could be that relative to the real world, the AMOC influence on extratropical NA SST is strongly underestimated in models exhibiting a large cold SST bias, which would have relevance to decadal predictability of extratropical NA SST and related quantities. By using very large ensembles, Smith et al. (2019) show that decadal climate is more predictable over the NA sector than previously thought. They discuss the signalto-noise paradox meaning that a climate model can predict the real world better than itself despite being an imperfect representation of the real world and a perfect representation of itself. We hypothesize that the skill of decadal predictions may be maintained at a similar level as in Smith et al. (2019), but with a smaller ensemble size if SST bias over the NA is reduced. We also note that the CMIP5 models exhibit a large spread with respect to the origin of NA SST variability.

One final implication of our study concerns the ongoing debate about the role of ocean dynamics in driving 
multidecadal climate variability over the NA sector. One aspect of this debate is around the SST-anomaly pattern associated with the NASST index derived from observations (Fig. 2a), which can be reproduced in simulations in which an atmospheric general circulation model is coupled to a slab ocean model without active ocean dynamics (Clement et al. 2015; Cane et al. 2017; Zhang 2017; Delworth et al. 2017). Clement et al. (2015) interpret the AMO as the response of the upper ocean mixed layer to heat-flux forcing by the atmosphere, which is associated with the NAO. Some of the confusion about the importance of ocean dynamics in NA SST variability may arise from the choice of the SST index. The mechanistic drivers influencing the NASST index can be thermodynamic and dynamic in nature. Furthermore, the different drivers operate on different time scales. Clement et al. (2015) use the NASST index to discuss the role of ocean dynamics in NA SST, which is based on annual SSTs, and this index has been shown here to lump together SST variability of different origin. The climate models used here suggest that the AMO index, which is defined in this study as the low-pass filtered NASST index, may be a better choice to identify ocean dynamical effects on NA SST.

However, when calculated from the short instrumental observations, the SST-anomaly pattern associated with the AMO index still resembles the pattern associated with the NASST index and likely contains large components from atmospheric heat-flux forcing, ocean dynamical heating, and external forcing. The E-NASST (extratropical NA SST) index, which is based on annual data, could be used instead of the AMO index to obtain some hint from instrumental SSTs about the oceancirculation influence on NA SST. This is because the multidecadal SST variability in many climate models mainly exists over the extratropical NA and is strongly linked to the AMOC and SPG, whereas the NASST index also includes the tropical NA SST variability that is mostly related to atmospheric heat-flux forcing in the models. Thus, on the one hand the E-NASST index strongly reflects the effects of the ocean circulation on multidecadal SST variability and on the other hand avoids the high-frequency tropical NA SST "noise." The E-NASST index therefore avoids the low-pass filter, which can reduce the temporal variability and make statistical tests less stringent (Ebisuzaki 1997). However, a more detailed approach is required instead of simple spatial averaging to clearly separate the different factors influencing NA SST, which would include other variables and more advanced statistical methods such as singular value decomposition (SVD) targeted at investigating the covariance between variables and regions.
Acknowledgments. We acknowledge the World Climate Research Programs Working Group on Coupled Modeling, the individual modeling groups of the Coupled Model Intercomparison Project phase 5 (CMIP5), the U.K. Met Office for providing the SST data, and the National Center for Atmospheric Research for the NAO data. The climate model integrations of the KCM were performed at the Computing Centre of Kiel University and the NorthGerman Supercomputing Alliance (HLRN). This work was supported by the European Union's CLIMPRE InterDec project (01LP1609B) and RACE II Project of BMBF (Grant Agreement 03F0729C) and was also funded in part by a $\mathrm{PhD}$ scholarship funded jointly by the China Scholarship Council (CSC). This is a contribution to the Cluster of Excellence "The Future Ocean" at the University of Kiel.

\section{REFERENCES}

Amaya, D. J., M. J. DeFlorio, A. J. Miller, and S.-P. Xie, 2017: WES feedback and the Atlantic meridional mode: Observations and CMIP5 comparisons. Climate Dyn., 49, 1665-1679, https:// doi.org/10.1007/s00382-016-3411-1.

Ba, J., and Coauthors, 2014: A multi-model comparison of Atlantic multidecadal variability. Climate Dyn., 43, 2333-2348, https:// doi.org/10.1007/s00382-014-2056-1.

Bellomo, K., L. N. Murphy, M. A. Cane, A. C. Clement, and L. M. Polvani, 2018: Historical forcings as main drivers of the Atlantic multidecadal variability in the CESM large ensemble. Climate Dyn., 50, 3687-3698, https://doi.org/10.1007/s00382017-3834-3.

Booth, B. B., N. J. Dunstone, P. R. Halloran, T. Andrews, and N. Bellouin, 2012: Aerosols implicated as a prime driver of twentieth-century North Atlantic climate variability. Nature, 484, 228-232, https://doi.org/10.1038/nature10946.

Brown, P. T., M. S. Lozier, R. Zhang, and W. Li, 2016: The necessity of cloud feedback for a basin-scale Atlantic Multidecadal Oscillation. Geophys. Res. Lett., 43, 3955-3963, https://doi.org/10.1002/2016GL068303.

Cane, M. A., A. C. Clement, L. N. Murphy, and K. Bellomo, 2017: Low-pass filtering, heat flux, and Atlantic multidecadal variability. J. Climate, 30, 7529-7553, https://doi.org/10.1175/ JCLI-D-16-0810.1.

Carton, J. A., X. Cao, B. S. Giese, and A. M. da Silva, 1996: Decadal and interannual SST variability in the tropical Atlantic Ocean. J. Phys. Oceanogr., 26, 1165-1175, https:/ doi.org/10.1175/1520-0485(1996)026<1165:DAISVI >2.0.CO;2.

Cayan, D. R., 1992: Latent and sensible heat flux anomalies over the northern oceans: Driving the sea surface temperature. J. Phys. Oceanogr., 22, 859-881, https://doi.org/10.1175/15200485(1992)022<0859:LASHFA > 2.0.CO;2.

Clement, A., K. Bellomo, L. N. Murphy, M. A. Cane, T. Mauritsen, G. Rädel, and B. Stevens, 2015: The Atlantic Multidecadal Oscillation without a role for ocean circulation. Science, 350, 320-324, https://doi.org/10.1126/science.aab3980.

Curry, R. G., and M. S. McCartney, 2001: Ocean gyre circulation changes associated with the North Atlantic Oscillation. J. Phys. Oceanogr., 31, 3374-3400, https://doi.org/10.1175/ 1520-0485(2001)031<3374:OGCCAW>2.0.CO;2. 
Danabasoglu, G., S. G. Yeager, Y. O. Kwon, J. J. Tribbia, A. S. Phillips, and J. W. Hurrell, 2012: Variability of the Atlantic meridional overturning circulation in CCSM4. J. Climate, 25 , 5153-5172, https://doi.org/10.1175/JCLI-D-11-00463.1.

Day, J. J., J. C. Hargreaves, J. D. Annan, and A. Abe-Ouchi, 2012: Sources of multi-decadal variability in Arctic sea ice extent. Environ. Res. Lett., 7, 034011, https://doi.org/10.1088/17489326/7/3/034011

Delworth, T. L., and M. E. Mann, 2000: Observed and simulated multidecadal variability in the Northern Hemisphere. Climate Dyn., 16, 661-676, https://doi.org/10.1007/s003820000075.

- , and F. Zeng, 2016: The impact of the North Atlantic Oscillation on climate through its influence on the Atlantic meridional overturning circulation. J. Climate, 29, 941-962, https://doi.org/10.1175/JCLI-D-15-0396.1.

- S. Manabe, and R. Stouffer, 1993: Interdecadal variations of the thermohaline circulation in a coupled ocean-atmosphere model. J. Climate, 6, 1993-2011, https://doi.org/10.1175/15200442(1993)006\%3C1993:IVOTTC\%3E2.0.CO;2.

— , F. Zeng, G. A. Vecchi, X. Yang, L. Zhang, and R. Zhang, 2016: The North Atlantic Oscillation as a driver of rapid climate change in the Northern Hemisphere. Nat. Geosci., 9, 509-512, https://doi.org/10.1038/ngeo2738.

- _ - L L. Zhang, R. Zhang, G. A. Vecchi, and X. Yang, 2017: The central role of ocean dynamics in connecting the North Atlantic Oscillation to the extratropical component of the Atlantic multidecadal oscillation. J. Climate, 30, 3789-3805, https://doi.org/10.1175/JCLI-D-16-0358.1.

Deser, C., and M. L. Blackmon, 1993: Surface climate variations over the North Atlantic Ocean during winter: 1900-1989. J. Climate, 6, 1743-1753, https://doi.org/10.1175/1520 0442(1993)006<1743:SCVOTN $>2.0 . \mathrm{CO} ; 2$.

Drews, A., and R. J. Greatbatch, 2016: Atlantic multidecadal variability in a model with an improved North Atlantic Current. Geophys. Res. Lett., 43, 8199-8206, https://doi.org/ 10.1002/2016GL069815.

—, and _ 2017: Evolution of the Atlantic multidecadal variability in a model with an improved North Atlantic Current J. Climate, 30, 5491-5512, https://doi.org/10.1175/JCLI-D-160790.1 .

Ebisuzaki, W., 1997: A method to estimate the statistical significance of a correlation when the data are serially correlated J. Climate, 10, 2147-2153, https://doi.org/10.1175/1520 0442(1997)010<2147:AMTETS>2.0.CO;2.

Eden, C., and T. Jung, 2001: North Atlantic interdecadal variability: Oceanic response to the North Atlantic Oscillation (18651997). J. Climate, 14, 676-691, https://doi.org/10.1175/15200442(2001)014<0676:NAIVOR >2.0.CO;2.

- and J. Willebrand, 2001: Mechanism of interannual to decadal variability of the North Atlantic circulation. J. Climate, 14, 2266-2280, https://doi.org/10.1175/1520-0442(2001) 014<2266:MOITDV>2.0.CO;2.

Enfield, D. B., and D. A. Mayer, 1997: Tropical Atlantic sea surface temperature variability and its relation to El Niño-Southern Oscillation. J. Geophys. Res., 102, 929-945, https://doi.org/ 10.1029/96JC03296.

_ A. M. Mestas-Nuñez, and P. J. Trimble, 2001: The Atlantic Multidecadal Oscillation and its relation to rainfall and river flows in the continental U.S. Geophys. Res. Lett., 28, 2077 2080, https://doi.org/10.1029/2000GL012745.

Folland, C. K., T. N. Palmer, and D. E. Parker, 1986: Sahel rainfall and worldwide sea temperatures, 1901-85. Nature, 320, 602607, https://doi.org/10.1038/320602a0.
Frankcombe, L. M., and M. H. England, 2015: Separating internal variability from the externally forced climate response. J. Climate, 28, 8184-8202, https://doi.org/10.1175/JCLI-D-15-0069.1.

Frankignoul, C., 1985: Sea surface temperature anomalies, planetary waves, and air-sea feedback in the middle latitudes. Rev. Geophys., 23, 357-390, https://doi.org/10.1029/RG023i004p00357.

Garuba, O. A., J. Lu, H. A. Singh, F. Liu, and P. Rasch, 2018: On the relative roles of the atmosphere and ocean in the Atlantic multidecadal variability. Geophys. Res. Lett., 45, 9186-9196, https://doi.org/10.1029/2018GL078882.

Goldenberg, S. B., C. W. Landsea, A. M. Mestas-Nuñez, and W. M. Gray, 2001: The recent increase in Atlantic hurricane activity: Causes and implications. Science, 293, 474-479, https://doi.org/ 10.1126/science. 1060040 .

Hodson, D. L., J. I. Robson, and R. T. Sutton, 2014: An anatomy of the cooling of the North Atlantic Ocean in the 1960s and 1970s. J. Climate, 27, 8229-8243, https://doi.org/10.1175/JCLID-14-00301.1.

Huang, B., and Coauthors, 2017: Extended Reconstructed Sea Surface Temperature version 5 (ERSSTv5): Upgrades, validations, and intercomparisons. J. Climate, 30, 8179-8205, https://doi.org/10.1175/JCLI-D-16-0836.1.

Hurrell, J. W., Y. Kushnir, G. Ottersen, and M. Visbeck, 2003: An overview of the North Atlantic Oscillation. The North Atlantic Oscillation: Climatic Significance and Environmental Impact, Geophys. Monogr., Vol. 134, Amer. Geophys. Union, 1-35, https://doi.org/10.1029/GM134.

Keenlyside, N. S., J. Ba, J. Mecking, N. E. Omrani, M. Latif, R. Zhang, and R. Msadek, 2016: North Atlantic multi-decadal variability-Mechanisms and predictability. Climate Change: Multidecadal and Beyond, C.-P. Chang et al., Eds., World Scientific Series on Asia-Pacific Weather and Climate, Vol. 6, World Scientific, 141-157.

Kerr, R. A., 2000: A North Atlantic climate pacemaker for the centuries. Science, 288, 1984-1985, https://doi.org/10.1126/ science.288.5473.1984

Kilbourne, K. H., T. M. Quinn, R. Webb, T. Guilderson, J. Nyberg, and A. Winter, 2008: Paleoclimate proxy perspective on Caribbean climate since the year 1751: Evidence of cooler temperatures and multidecadal variability. Paleoceanography, 23, PA3220, https://doi.org/10.1029/2008PA001598.

Kim, W. M., S. Yeager, P. Chang, and G. Danabasoglu, 2018a: Low-frequency North Atlantic climate variability in the Community Earth System Model large ensemble. J. Climate, 31, 787-813, https://doi.org/10.1175/JCLI-D-17-0193.1.

, _ - and G. Danabasoglu, 2018b: Key role of internal ocean dynamics in Atlantic multidecadal variability during the last half century. Geophys. Res. Lett., 45, 13 449-13 457, https:// doi.org/10.1029/2018GL080474.

Knight, J. R., R. J. Allan, C. K. Folland, M. Vellinga, and M. E. Mann, 2005: A signature of persistent natural thermohaline circulation cycles in observed climate. Geophys. Res. Lett., 32, L20708, https://doi.org/10.1029/2005GL024233.

Kushnir, Y., 1994: Interdecadal variations in North Atlantic sea surface temperature and associated atmospheric conditions. J. Climate, 7, 141-157, https://doi.org/10.1175/1520-0442(1994) 007\%3C0141:IVINAS\%3E2.0.CO;2.

, R. Seager, J. Miller, and J. C. Chiang, 2002: A simple coupled model of tropical Atlantic decadal climate variability. Geophys. Res. Lett., 29, 2133, https://doi.org/10.1029/2002GL015874.

Latif, M., and N. S. Keenlyside, 2011: A perspective on decadal climate variability and predictability. Deep-Sea Res. II, 58, 1880-1894, https://doi.org/10.1016/j.dsr2.2010.10.066. 
and Coauthors, 2004: Reconstructing, monitoring, and predicting multidecadal-scale changes in the North Atlantic thermohaline circulation with sea surface temperature. J. Climate, 17, 16051614, https://doi.org/10.1175/1520-0442(2004)017<1605: RMAPMC $>2.0 . \mathrm{CO} ; 2$.

Locarnini, R. A., and Coauthors, 2018: Temperature. Vol. 1, World Ocean Atlas 2018, NOAA Atlas NESDIS 81, 52 pp.

Madec, G., 2008: NEMO ocean engine. Note du Pole de modélisation, Institut Pierre-Simon Laplace (IPSL), 27. Tech. rep. ISSN-1288-1619, 396 pp., https://www.nemo-ocean.eu/ wp-content/uploads/NEMO_book.pdf.

Mann, M. E., and K. Emanuel, 2006: Atlantic hurricane trends linked to climate change. Eos, Trans. Amer. Geophys. Union, 87, 233-244, https://doi.org/10.1029/2006EO240001.

Marshall, J., H. Johnson, and J. Goodman, 2001: A study of the interaction of the North Atlantic Oscillation with ocean circulation. J. Climate, 14, 1399-1421, https://doi.org/10.1175/ 1520-0442(2001)014<1399:ASOTIO>2.0.CO;2.

Martin, T., A. Reintges, and M. Latif, 2019: Coupled North Atlantic sub-decadal variability in CMIP5 models. J. Geophys. Res. Oceans, 124, 2404-2417, https://doi.org/10.1029/2018JC014539.

McCarthy, G. D., I. D. Haigh, J. J.-M. Hirschi, J. P. Grist, and D. A. Smeed, 2015: Ocean impact on decadal Atlantic climate variability revealed by sea-level observations. Nature, 521, 508510, https://doi.org/10.1038/nature14491.

Msadek, R., W. E. Johns, S. G. Yeager, G. Danabasoglu, T. L. Delworth, and A. Rosati, 2013: The Atlantic meridional heat transport at $26.5^{\circ} \mathrm{N}$ and its relationship with the MOC in the RAPID array and the GFDL and NCAR coupled models. J. Climate, 26, 4335-4356, https://doi.org/10.1175/JCLI-D-12-00081.1.

Nigam, S., A. Ruiz-Barradas, and L. Chafik, 2018: Gulf Stream excursions and sectional detachments generate the decadal pulses in the Atlantic multidecadal oscillation. J. Climate, 31, 2853-2870, https://doi.org/10.1175/JCLI-D-17-0010.1.

O'Reilly, C. H., M. Huber, T. Woollings, and L. Zanna, 2016: The signature of low-frequency oceanic forcing in the Atlantic Multidecadal Oscillation. Geophys. Res. Lett., 43, 2810-2818, https://doi.org/10.1002/2016GL067925.

Otterå, O. H., M. Bentsen, H. Drange, and L. Suo, 2010: External forcing as a metronome for Atlantic multidecadal variability. Nat. Geosci., 3, 688-694, https://doi.org/10.1038/ngeo955.

Park, T., W. Park, and M. Latif, 2016: Correcting North Atlantic sea surface salinity biases in the Kiel Climate Model: Influences on ocean circulation and Atlantic Multidecadal Variability. Climate Dyn., 47, 2543-2560, https://doi.org/ 10.1007/s00382-016-2982-1.

Park, W., N. Keenlyside, M. Latif, A. Ströh, R. Redler, E. Roeckner, and G. Madec, 2009: Tropical Pacific climate and its response to global warming in the Kiel Climate Model. J. Climate, 22, 71-92, https://doi.org/10.1175/2008JCLI2261.1.

Pearson, K., 1895: Notes on regression and inheritance in the case of two parents. Proc. Roy. Soc. London, 58, 240-242, https:// doi.org/10.1098/rspl.1895.0041.

Reintges, A., M. Latif, and W. Park, 2016: Sub-decadal North Atlantic Oscillation variability in observations and the Kiel Climate Model. Climate Dyn., 48, 3475-3487, https://doi.org/ 10.1007/s00382-016-3279-0.

Robson, J., R. Sutton, K. Lohmann, D. Smith, and M. Palmer, 2012: Causes of the rapid warming of the North Atlantic Ocean in the mid-1990s. J. Climate, 25, 4116-4134, https://doi.org/ 10.1175/JCLI-D-11-00443.1.

- — - and D. Smith, 2014: Decadal predictions of the cooling and freshening of the North Atlantic in the 1960s and the role of ocean circulation. Climate Dyn., 42, 2353-2365, https:// doi.org/10.1007/s00382-014-2115-7.

Roeckner, E., and Coauthors, 2003: The atmospheric general circulation model ECHAM 5: Part I: Max-Planck-Institut für Meteorlogie Rep. 349, 140 pp.

Rowell, D. P., C. K. Folland, K. Maskell, and M. N. Ward, 1995: Variability of summer rainfall over tropical North Africa (1906-92): Observations and modelling. Quart. J. Roy. Meteor Soc., 121, 669-704, https://doi.org/10.1002/QJ.49712152311.

Ruprich-Robert, Y., R. Msadek, F. Castruccio, S. Yeager, T. Delworth, and G. Danabasoglu, 2017: Assessing the climate impacts of the observed Atlantic multidecadal variability using the GFDL CM2.1 and NCAR CESM1 global coupled models. J. Climate, 30, 2785-2810, https://doi.org/10.1175/ JCLI-D-16-0127.1.

Smith, D. M., and Coauthors, 2019: Robust skill of decadal climate predictions. npj Climate Atmos. Sci., 2, 13, https://doi.org/ 10.1038/s41612-019-0071-y.

Sun, C., J. Li, and F.-F. Jin, 2015: A delayed oscillator model for the quasi-periodic multidecadal variability of the NAO. Climate Dyn., 45, 2083-2099, https://doi.org/10.1007/s00382-014-2459-z.

Sutton, R. T., and D. L. Hodson, 2005: Atlantic Ocean forcing of North American and European summer climate. Science, $\mathbf{3 0 9}$, 115-118, https://doi.org/10.1126/science.1109496.

Swart, N. C., J. C. Fyfe, E. Hawkins, J. E. Kay, and A. Jahn, 2015 Influence of internal variability on Arctic sea-ice trends. Nat. Climate Change, 5, 86-89, https://doi.org/10.1038/nclimate2483.

Taylor, K. E., R. J. Stouffer, and G. A. Meehl, 2012: An overview of CMIP5 and the experiment design. Bull. Amer. Meteor. Soc., 93, 485-498, https://doi.org/10.1175/BAMS-D-11-00094.1.

Thompson, R. O., 1979: Coherence significance levels. J. Atmos. Sci., 36, 2020-2021, https://doi.org/10.1175/1520-0469(1979) 036<2020:CSL>2.0.CO;2.

Timmermann, A., M. Latif, R. Voss, and A. Grötzner, 1998: Northern Hemispheric interdecadal variability: A coupled air-sea mode. J. Climate, 11, 1906-1931, https://doi.org/ 10.1175/1520-0442-11.8.1906.

Ting, M., Y. Kushnir, R. Seager, and C. Li, 2009: Forced and internal twentieth-century SST trends in the North Atlantic. J. Climate, 22, 1469-1481, https://doi.org/10.1175/2008JCLI2561.1.

,-- , and C. Li, 2014: North Atlantic multidecadal SST oscillation: External forcing versus internal variability. J. Mar. Syst., 133, 27-38, https://doi.org/10.1016/j.jmarsys.2013.07.006.

Trenberth, K. E., and D. J. Shea, 2006: Atlantic hurricanes and natural variability in 2005. Geophys. Res. Lett., 33, L12704, https://doi.org/10.1029/2006GL026894.

Valcke, S., E. Guilyardi, and C. Larsson, 2006: PRISM and ENES: A European approach to Earth system modelling. Concurr. Comput.: Pract. Exper., 18, 247-262, https://doi.org/10.1002/cpe.915.

Venzke, S., M. R. Allen, R. T. Sutton, and D. P. Rowell, 1999: The atmospheric response over the North Atlantic to decadal changes in sea surface temperature. J. Climate, 12, 2562-2584, https:// doi.org/10.1175/1520-0442(1999)012<2562:TAROTN>2.0.CO;2.

von Storch, H., and F. W. Zwiers, 2001: Statistical Analysis in Climate Research. Cambridge University Press, 484 pp.

Wang, C., and L. Zhang, 2013: Multidecadal ocean temperature and salinity variability in the tropical North Atlantic: Linking with the AMO, AMOC, and subtropical cell. J. Climate, 26, 6137-6162, https://doi.org/10.1175/JCLI-D-12-00721.1.

, S. Dong, and E. Munoz, 2010: Seawater density variations in the North Atlantic and the Atlantic meridional overturning circulation. Climate Dyn., 34, 953-968, https://doi.org/10.1007/ s00382-009-0560-5. 
Welch, P. D., 1967: The use of fast Fourier transform for the estimation of power spectra: A method based on time averaging over short, modified periodograms. IEEE Trans. Audio Electroacoust., 15, 70-73, https://doi.org/10.1109/TAU.1967.1161901.

Wills, R. C., K. C. Armour, D. S. Battisti, and D. L. Hartmann, 2019: Ocean-atmosphere dynamical coupling fundamental to the Atlantic multidecadal oscillation. J. Climate, 32, 251-272, https://doi.org/10.1175/JCLI-D-18-0269.1.

Xie, S.-P., and S. G. H. Philander, 1994: A coupled oceanatmosphere model of relevance to the ITCZ in the eastern Pacific. Tellus, 46A, 340-350, https://doi.org/10.3402/ tellusa.v46i4.15484.

—, and J. A. Carton, 2004: Tropical Atlantic variability: Patterns, mechanisms, and impacts. The Ocean-Atmosphere Interaction, Geophys. Monogr., Vol. 147, Amer. Geophys. Union, 121-142.

Yan, X., R. Zhang, and T. R. Knutson, 2019: A multivariate AMV index and associated discrepancies between observed and CMIP5 externally forced AMV. Geophys. Res. Lett., 46, 44214431, https://doi.org/10.1029/2019GL082787.

Yuan, T., L. Oreopoulos, M. Zelinka, H. Yu, J. R. Norris, M. Chin, S. Platnick, and K. Meyer, 2016: Positive low cloud and dust feedbacks amplify tropical North Atlantic Multidecadal Oscillation. Geophys. Res. Lett., 43, 1349-1356, https://doi.org/ 10.1002/2016GL067679.

Zhang, J., and R. Zhang, 2015: On the evolution of Atlantic Meridional Overturning Circulation fingerprint and implications for decadal predictability in the North Atlantic. Geophys. Res. Lett., 42, 5419-5426, https://doi.org/10.1002/ 2015 GL064596.

Zhang, L., and C. Wang, 2013: Multidecadal North Atlantic sea surface temperature and Atlantic meridional overturning circulation variability in CMIP5 historical simulations.
J. Geophys. Res. Oceans, 118, 5772-5791, https://doi.org/ 10.1002 /jgrc. 20390.

and C. Zhao, 2015: Processes and mechanisms for the model SST biases in the North Atlantic and North Pacific: A link with the Atlantic meridional overturning circulation. J. Adv. Model. Earth Syst., 7, 739-758, https://doi.org/10.1002/ 2014MS000415.

Zhang, R., 2007: Anticorrelated multidecadal variations between surface and subsurface tropical North Atlantic. Geophys. Res. Lett., 34, L12713, https://doi.org/10.1029/2007GL030225.

2010: Latitudinal dependence of Atlantic meridional overturning circulation (AMOC) variations. Geophys. Res. Lett., 37, L16703, https://doi.org/10.1029/2010GL044474.

2017: On the persistence and coherence of subpolar sea surface temperature and salinity anomalies associated with the Atlantic multidecadal variability. Geophys. Res. Lett., 44, 7865-7875, https://doi.org/10.1002/2017GL074342.

— a substantial weakening of the Atlantic thermohaline circulation. J. Climate, 18, 1853-1860, https://doi.org/10.1175/ JCLI3460.1.

, and Coauthors, 2013: Have aerosols caused the observed Atlantic multidecadal variability? J. Atmos. Sci., 70, 11351144, https://doi.org/10.1175/JAS-D-12-0331.1.

—, R. Sutton, G. Danabasoglu, T. L. Delworth, W. M. Kim, J. Robson, and S. G. Yeager, 2016: Comment on "The Atlantic Multidecadal Oscillation without a role for ocean circulation." Science, 352, 1527, https://doi.org/10.1126/science.aaf1660.

Y. O. Kwon, R. Marsh, S. G. Yeager, D. E. Amrhein, and C. M. Little, 2019: A review of the role of the Atlantic Meridional Overturning Circulation in Atlantic multidecadal variability and associated climate impacts. Rev. Geophys., 57, 316-375, https://doi.org/10.1029/2019RG000644. 